\title{
An Integrated Cytoskeletal Model of Neurite Outgrowth
}

\author{
Kyle E. Miller ${ }^{1 *}$ and Daniel M. Suter $2,3,4,5 *$ \\ ${ }^{1}$ Department of Integrative Biology, Michigan State University, East Lansing, MI, United States, ${ }^{2}$ Department of Biological \\ Sciences, Purdue University, West Lafayette, IN, United States, ${ }^{3}$ Purdue Institute for Integrative Neuroscience, Purdue \\ University, West Lafayette, IN, United States, ${ }^{4}$ Bindley Bioscience Center, Purdue University, West Lafayette, IN, \\ United States, ${ }^{5}$ Birck Nanotechnology Center, Purdue University, West Lafayette, IN, United States
}

\section{OPEN ACCESS}

Edited by: Peter S. Steyger,

Oregon Health \& Science University, United States

Reviewed by: Victor Shing Chi Wong, Weill Cornell Medicine - Cornell University, United States Francisco F. De-Miguel, Universidad Nacional Autónoma de México, Mexico

*Correspondence: Kyle E. Miller kmiller@msu.edu Daniel M. Suter dsuter@purdue.edu

Received: 13 September 2018 Accepted: 07 November 2018 Published: 26 November 2018

Citation:

Miller KE and Suter DM (2018) An Integrated Cytoskeletal Model of Neurite Outgrowth Front. Cell. Neurosci. 12:447. doi: $10.3389 /$ fncel.2018.00447
Neurite outgrowth underlies the wiring of the nervous system during development and regeneration. Despite a significant body of research, the underlying cytoskeletal mechanics of growth and guidance are not fully understood, and the relative contributions of individual cytoskeletal processes to neurite growth are controversial. Here, we review the structural organization and biophysical properties of neurons to make a semi-quantitative comparison of the relative contributions of different processes to neurite growth. From this, we develop the idea that neurons are active fluids, which generate strong contractile forces in the growth cone and weaker contractile forces along the axon. As a result of subcellular gradients in forces and material properties, actin flows rapidly rearward in the growth cone periphery, and microtubules flow forward in bulk along the axon. With this framework, an integrated model of neurite outgrowth is proposed that hopefully will guide new approaches to stimulate neuronal growth.

Keywords: active matter, actin, axonal elongation, axonal transport, dynein, growth cone, microtubule, nonmuscle myosin II

\section{INTRODUCTION}

Neurite outgrowth is essential for wiring the nervous system during development and regeneration following trauma or disease (Suter and Miller, 2011; Kulkarni and Firestein, 2012; Budday et al., 2014; Hilton and Bradke, 2017; Stoeckli, 2018). Despite a significant body of research conducted over the last three decades, the underlying mechanisms of axonal growth and guidance are not fully understood, especially at the interface of dynamics and mechanics (Suter and Miller, 2011; Leterrier et al., 2017). Quoting Benford's Law of Controversy, "Passion is inversely proportional to the amount of real information available" (Benford, 1980), we are excited to bring together quantitative data acquired by many labs to develop a mechanical model of neurite growth. The strength of this approach is that because forces can be mathematically integrated, the relative contributions of different processes can be impartially considered in a single framework. We begin this review by discussing the structural organization of neurons focusing on the actin and MT cytoskeleton. We then briefly summarize recent studies on the biophysics of growth cones and axons and use this perspective to discuss the cell biology of actin and MT dynamics, cellular adhesions, molecular force generation, and cytoskeletal cross-linkers. In the last sections, we discuss some of the "controversial" findings in this field in light of a more integrated model of neurite growth. Throughout this review, we develop the idea that neurons are active fluids, which generate

Abbreviations: EB, end-binding proteins; MT, microtubule; NGF, nerve growth factor; NMII, non-muscle myosin II. 
strong contractile forces in the growth cone and weaker contractile forces along the axon through multiple interacting processes (O'Toole et al., 2015; de Rooij et al., 2018). As a result of subcellular gradients in forces, viscosity, and substrate adhesions, actin flows rapidly rearward in the growth cone periphery, and MTs flow forward in bulk along the axon (Athamneh et al., 2017). From this, a picture emerges that a growth cone is much like a migrating cell coupled to the cell body by the axon, much like "a leukocyte on a leash" (Pfenninger, 1986). Forces and cytoskeletal dynamics in the growth cone control its advance, while the axon acts to restrain and support growth cone motility. The significant difference of the present to previous models is that the growth cone advances as a coherent structure and pulls the adjacent axon forward, instead of elongating by the assembly of MTs at the tip of the axon (Dent and Gertler, 2003; Cammarata et al., 2016; Blanquie and Bradke, 2018). We conclude this review by touching on the implications of this updated model for developing approaches to promote rapid axonal elongation.

\section{NEURONAL STRUCTURE}

\section{The Structure of the Growth Cone}

The highly motile structure at the tip of growing axons and dendrites is called the growth cone. Its key function in establishing the complex neuronal networks in the nervous system was recognized by Ramón y Cajal over 100 years ago. The two most critical cytoskeletal proteins involved in neurite outgrowth and guidance are actin filaments and MTs. Here, we briefly summarize their organization and dynamics including assembly, translocation, stabilization, and turnover to develop a foundation for understanding the mechanical process of neurite outgrowth. Several excellent reviews of these processes have been published recently (Coles and Bradke, 2015; Kapitein and Hoogenraad, 2015; Cammarata et al., 2016; Letourneau, 2016; Matamoros and Baas, 2016; Voelzmann et al., 2016; Omotade et al., 2017); therefore, we will not cover them in detail here.

The growth cone is usually divided into three morphologically and functionally distinct cytoplasmic regions: (1) the peripheral domain, which is made up by filopodia and intervening lamellipodial veils; (2) the transition zone; and (3) the central domain, which is rich in various organelles including mitochondria (Figure 1). F-actin is the predominant cytoskeletal structure in the peripheral domain and transition zone, and at least four different subpopulations of F-actin structures are recognized in the growth cone. In the periphery, polarized bundles of 15-20 actin filaments provide the core structure of filopodia (Figure 1B), fingerlike protrusions that dynamically explore the environment for guidance information (Lewis and Bridgman, 1992; Davenport et al., 1993; Korobova and Svitkina, 2008; Gallo, 2013). The lamellipodia (Figure 1B) between the filopodia are filled with a dense, branched F-actin network, whose constant turnover drives the forward movement of the growth cone (Lewis and Bridgman, 1992; Small et al., 2002; Mongiu et al., 2007). The third subtype of F-actin structures are the transverse actin arcs that surround the central domain and control its shape as well as the distribution of MTs (Schaefer et al., 2002, 2008;

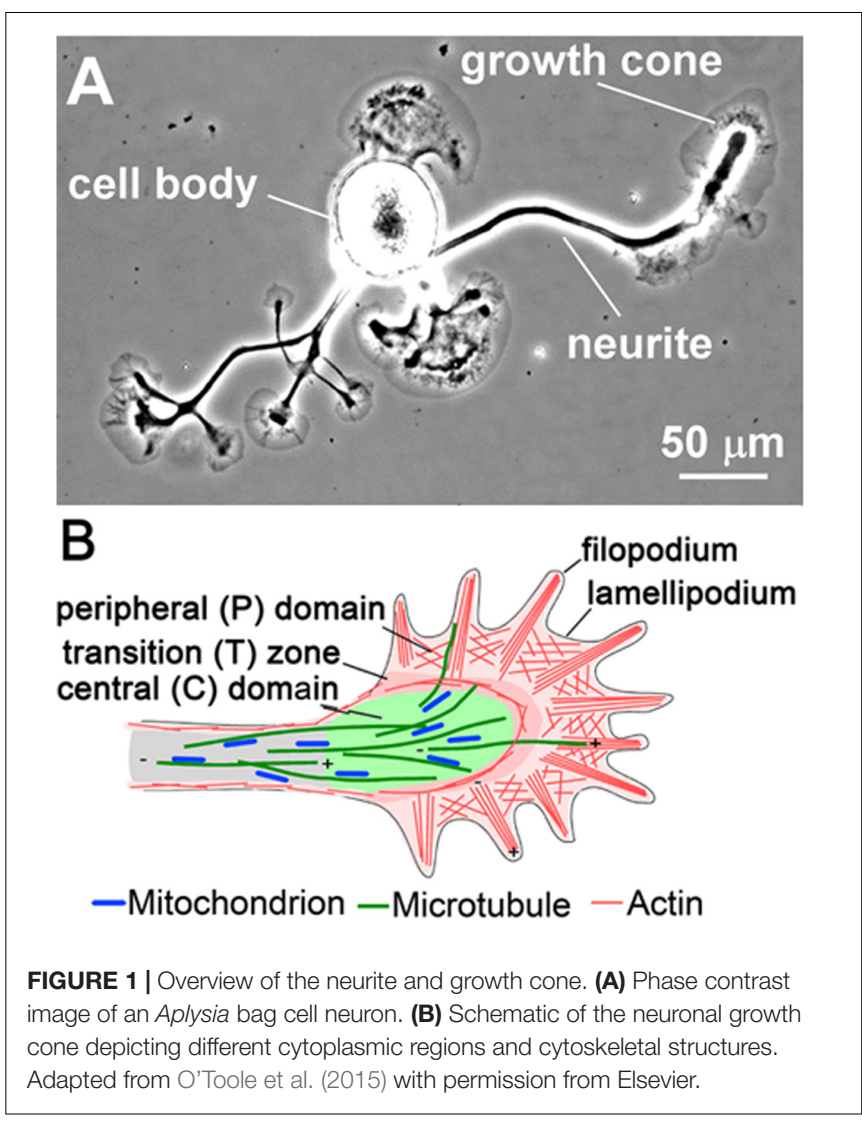

Zhang et al., 2003). Lastly, the fourth F-actin structure is the dynamically rearranging intrapodia or ruffles in the transition zone (Rochlin et al., 1999), which recently have been suggested to promote traction force generation by buffering developing adhesion sites from the effects of retrograde flow (Buck et al., 2017).

The F-actin structures in the peripheral domain and transition zone are highly dynamic and turnover within a few minutes. Actin assembly occurs at the plus ends of filaments at filopodial tips and along the leading edge of lamellipodia to push the plasma membrane forward (Mallavarapu and Mitchison, 1999; Shahapure et al., 2010; Amin et al., 2012; Craig et al., 2012; Van Goor et al., 2012; Lee et al., 2013; Figure 2). Following assembly, F-actin moves by a process referred to as "retrograde actin flow," which is mainly dependent on NMII (Medeiros et al., 2006). Lastly, actin filaments are disassembled in the transition zone by ADF/ cofilin (Marsick et al., 2010; Flynn et al., 2012; Omotade et al., 2017) and other proteins such as gelsolin (Lu et al., 1997). G-actin is transported to the leading edge to complete the cycle (Lee et al., 2013). As will be discussed below in more detail, a major function of these processes is to generate the forces needed for MT advance.

\section{The Structure of the Axon}

\section{Actin in the Axon}

Whereas a significant body of literature has described the organization and dynamics of F-actin in the neuronal growth 


\begin{tabular}{|c|c|c|}
\hline Symbol & $\begin{array}{c}\text { Structure / } \\
\text { Protein }\end{array}$ & Function \\
\hline & $\begin{array}{l}\text { Plasma } \\
\text { membrane }\end{array}$ & $\begin{array}{l}\text { Supports membrane tension } \\
\text { and regulates cell volume }\end{array}$ \\
\hline & $\begin{array}{c}\text { MT with } \\
+ \text { TIP proteins - } \\
\text { EB1 } \\
\end{array}$ & $\begin{array}{l}\text { Control of MT dynamics and } \\
\text { extensile force generation }\end{array}$ \\
\hline & $\begin{array}{l}\text { Point contact - } \\
\text { vinculin, integrin, } \\
\text { and laminin }\end{array}$ & $\begin{array}{l}\text { Couples actin to substrate } \\
\text { to generate traction force }\end{array}$ \\
\hline & $\begin{array}{c}\text { Actin assembly } \\
\text { at membrane - } \\
\text { formins }\end{array}$ & $\begin{array}{l}\text { Pushes membrane } \\
\text { forward \& actin backwards }\end{array}$ \\
\hline & $\begin{array}{l}\text { Contractile node in } \\
\text { transition zone - } \\
\text { NMIIB, NMIIC, } \\
\text { and ADF/cofilin }\end{array}$ & $\begin{array}{l}\text { Pulls peripheral } \\
\text { domain rearwards, } \\
\text { actin arcs forward, and } \\
\text { disassembles actin }\end{array}$ \\
\hline & $\begin{array}{c}\text { MT/actin } \\
\text { crosslinker - } \\
\text { spectraplakin or tau }\end{array}$ & $\begin{array}{l}\text { Reinforces MTs } \\
\text { and transfers forces } \\
\text { between elements }\end{array}$ \\
\hline & $\begin{array}{l}\text { MT cross linker - } \\
\text { tau }\end{array}$ & $\begin{array}{c}\text { Bundles MTs, } \\
\text { decreases buckling, } \\
\text { permits long distance } \\
\text { force propagation }\end{array}$ \\
\hline & $\begin{array}{l}\text { MT motor - } \\
\text { dynein }\end{array}$ & $\begin{array}{l}\text { Slides MT apart } \\
\text { to generate } \\
\text { extensile forces }\end{array}$ \\
\hline$\frac{0}{1}$ & $\begin{array}{l}\text { Axonal actin motor - } \\
\text { NMIIA }\end{array}$ & $\begin{array}{l}\text { Generates contractile force } \\
\text { that controls axonal diameter } \\
\text { and opposes elongation }\end{array}$ \\
\hline$I \square$ & $\begin{array}{l}\text { Cortical meshwork - } \\
\text { actin and spectrin }\end{array}$ & $\begin{array}{l}\text { Promotes } \\
\text { axonal } \\
\text { integrity }\end{array}$ \\
\hline \# & Axonal adhesion & $\begin{array}{c}\text { Generates friction } \\
\text { that suppresses } \\
\text { bulk flow }\end{array}$ \\
\hline
\end{tabular}

B Structure

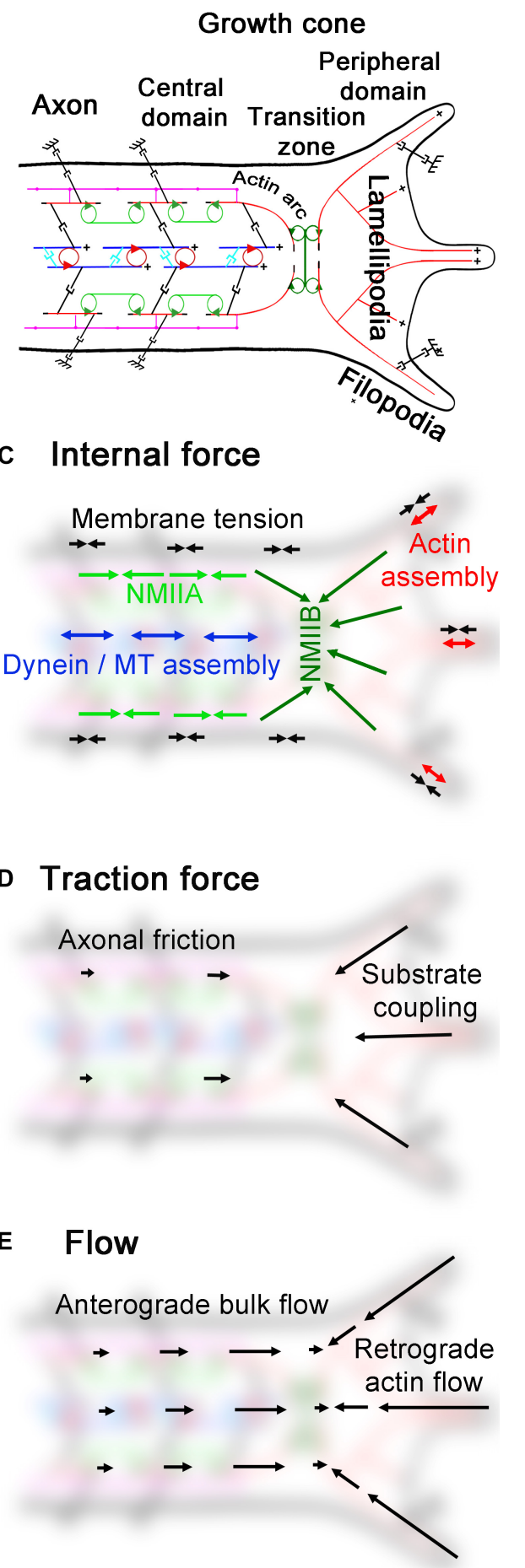

FIGURE 2 | An integrated cytoskeletal model of neurite outgrowth. (A) Summary of the mechanisms, structures/proteins, and functions reviewed in the manuscript. (B) A diagram of the interrelationship between the structures. (C) Overview of significant sources of internal force generation; arrows pointing together indicate a contractile force dipole, a line with arrowheads on each end represents an extensile force dipole. The length of the arrows (or pairs of arrows) gives a relative indication of the force associated with each process. (D) Traction forces exerted on the substrate; the length of the arrows indicates relative magnitude. (E) Flow map, arrow length indicates relative velocity. The force and velocity vectors are shown over a blurred image of the underlying structure to give a sense of relative location. 
cone, less is known about the details of the F-actin cytoskeleton in the axon. Nonetheless, due to the recent developments in super-resolution microscopy, this is now rapidly changing with the recognition of actin rings, waves, trails, and patches (Roy, 2016; Leterrier et al., 2017; Papandreou and Leterrier, 2018). Of particular relevance to neuronal mechanics are actin ring structures in axons, which are capped at the plus ends by adducin and spaced at roughly $190 \mathrm{~nm}$ intervals by spectrin (Xu et al., 2013; Zhong et al., 2014; D’Este et al., 2015; Papandreou and Leterrier, 2018). While the function of the rings is still being determined, there are several lines of evidence suggesting that they play a key role in axonal mechanics along with the axonal actin cortex. In particular, spectrin is essential for maintaining the structural integrity of axons by resisting the stresses and strains arising from body motion (Hammarlund et al., 2007; Krieg et al., 2017). Likewise, NMII and adducin have an overlapping periodicity with the actin rings (Leite et al., 2016; Berger et al., 2018), and regulate axonal diameter (Leite et al., 2016; Fan et al., 2017). Since actin and NMII also drive axonal contraction and retraction (Joshi et al., 1985; Tofangchi et al., 2016), the actomyosin cortex appears to produce contractile forces both circumferentially and longitudinally along the length of the axons (Figure 3).

Whereas early models of actin rings proposed short filaments of $\sim 20 \mathrm{~nm}$ arranged in a circle (Xu et al., 2013), the length of these actin filaments (Jones and Svitkina, 2016) and their directionality remain unclear (Berger et al., 2018). In particular, electron microscopy has indicated that the cortical axonal actin is a random or weakly ordered meshwork of filaments with a length of roughly $1.5 \mu \mathrm{m}$ (Hirokawa, 1982; Bearer and Reese, 1999; Leterrier et al., 2017). In addition, longer longitudinal actin structures with a mean length of $9 \mu \mathrm{m}$ called trails (Ganguly et al., 2015) have been observed in many super-resolution studies (D'Este et al., 2015; Leite et al., 2016). Reconciling the observations of periodicity, a meshwork like organization, and NMII-driven contraction suggests the possibility that actin is a weakly ordered meshwork (Figure 3) that has periodic differences in density in mature axons that appear as rings. As

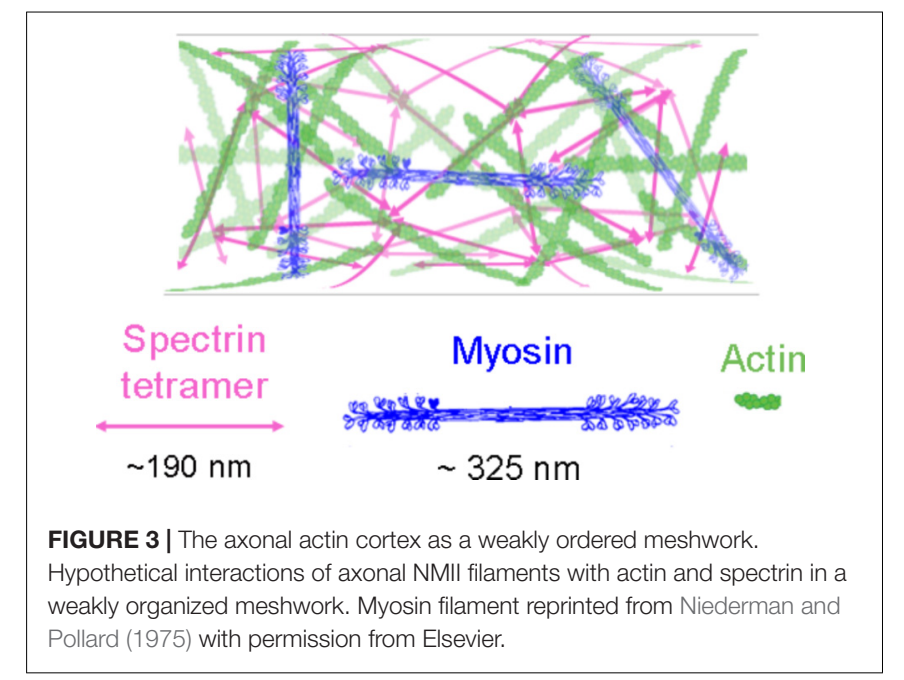

NMII filaments are $~ 300 \mathrm{~nm}$ long (Billington et al., 2013), they may wrap around the axon to generate a circumferential force (Berger et al., 2018), and span or lie diagonally between rings to generate a longitudinal force (de Rooij et al., 2018; Mutalik et al., 2018). In parallel, NMII filaments interconnecting trails (Ganguly et al., 2015) may generate forces that are propagated over long distances. This supports a speculative mechanistic hypothesis for the observations that axons, away from the growth cone, generate a net contractile force of $\sim 0.6 \mathrm{nN}$ (O'Toole et al., 2015), NMII drives axonal contraction and retraction (Wylie and Chantler, 2003; Gallo, 2006; Myers et al., 2006; Brown et al., 2009; Tofangchi et al., 2016; Mutalik et al., 2018), and NMII generates contractile forces that control axonal diameter (Fan et al., 2017). As structure and function are intertwined, bridging the gap between the superresolution imaging, electron microscopy, and biophysical studies seems likely to be a fruitful direction for investigations aimed at understanding neuronal mechanics.

\section{MT Polarity and Length During Axonal Elongation}

In combination with F-actin, MTs are essential for axonal elongation and growth cone guidance (Coles and Bradke, 2015; Kapitein and Hoogenraad, 2015; Letourneau, 2016). Like actin filaments, MTs are polarized structures with polymerization occurring at their plus ends by the addition of tubulin dimers. In higher organisms, the majority of MTs have their plus ends oriented toward the axonal terminal, whereas dendrites exhibit a more mixed polarity (Baas et al., 1988; Yau et al., 2016). MT polarity is critical for the polarized organization of neurons, as it underlies the directional transport of proteins and organelles (Maday et al., 2014; Leterrier et al., 2017), the establishment of axon vs. dendrite identity (Rolls and Jegla, 2015), and the generation of forces through MT sliding (Jakobs et al., 2015; Kapitein and Hoogenraad, 2015; Kahn and Baas, 2016; de Rooij et al., 2017; Lu and Gelfand, 2017). As development progresses, MT polarity in neuronal processes becomes more ordered (van Beuningen et al., 2015). In lower organisms, such as Drosophila and C. elegans, dendritic MTs initially have a mixed polarity, which transitions to a nearly uniform minus ends out orientation (Maniar et al., 2011; Hill et al., 2012). Likewise in axons, the polarity of MTs increases over time. As an example in rat cortical neurons initially $\sim 80 \%$ of the MTs point toward the growth cone, but in mature axons nearly all do so (Baas et al., 1989; Yau et al., 2016; Figure 4).

In parallel to these changes in MT polarity, there are dramatic changes in the length and number of MT during development. Building on classic electron microscopy studies (Chalfie and Thomson, 1979; Bray and Bunge, 1981; Burton, 1987; Yu and Baas, 1994), a recent analysis in C. elegans provides new insights in how MTs are added to growing axons and its impact on organelle transport (Yogev et al., 2016). Using an innovative image analysis approach, the authors quantified the number, length and spacing of MTs in specific axons of in living worms. They achieved this by correlating the intensities of single MTs with the intensity of tubulin-GFP along the axon to determine the beginning and end of individual MTs. This approach has the advantages over electron microscopy in that data can be collected rapidly without time-consuming sample preparations and that 


\section{A Initial outgrowth}

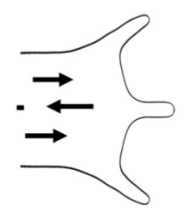

\section{B Neuritogenesis}
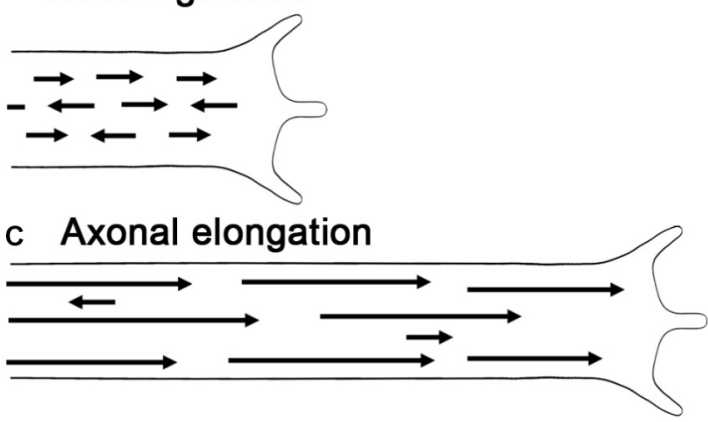

FIGURE 4 | Microtubule polarity and length increase during axonal outgrowth. (A) Initial growth cone with the arrows representing the length and orientation of MTs. (B) During neurogenesis, MT sliding adds new short MTs with mixed orientations. (C) As axons elongate polarity and MT length increase, while sliding and MT number decrease.

MT dynamics can be observed directly. Examining the length and distribution of MTs from an early larval stage to adulthood, average MT length doubled from about 4 to $8 \mu \mathrm{m}$, and the number of MT per cross-section increased at a similar rate. Over this same time, axonal length increased by a factor of 3.5 as the result of body growth. Somewhat surprisingly the spacing between adjacent MT minus ends, a measure of MT density, remained constant. As body growth causes axons to lengthen by stretching (Smith, 2009; O'Toole and Miller, 2011; Loverde and Pfister, 2015) it is tempting to speculate that as axons stretch, the spacing between the minus ends of MTs already in the axon increases, and new MTs are added in the gaps. Since the density of MT minus ends remains constant through development, the increase in the number of MTs per cross-section may be accounted for by the increase in MT length.

These data complement, but differ somewhat from earlier work using electron microscopy in vertebrates. In hippocampal neurons during the process when a minor stage 3 process (length $\leq 20 \mu \mathrm{m}$ ) transitions into a stage 3 axon (length $\geq 50 \mu \mathrm{m})$, MT length is short $(\sim 4 \mu \mathrm{m})$, and increased axonal length is associated with a rise in the number of MTs and not their average length (Yu and Baas, 1994). In contrast, going from a stage 3 axon to stage 4 axon, there is a large drop in the number of MTs and increase in MT length. Likewise, as axons mature over weeks to months, MT length reaches hundreds of $\mu \mathrm{m}$ and their number declines both in vitro and in vivo (Bray and Bunge, 1981; Burton, 1987). Keeping in mind that $C$. elegans development occurs over a few days and the study from Shen's group focused on a period where axons were lengthening (Yogev et al., 2016), a general picture emerges. Early in the process of neurite outgrowth, axonal lengthening is associated with an increase in MT number and an increase in the average or the range of MT lengths. In vertebrates, this is followed by a substantial increase in MT length and drop in MT number (Figure 4). These observations provide a foundation for understanding neurite outgrowth since MT length and number are tightly linked to sliding and the addition of MTs to growing axons.

\section{MT TRANSPORT AND NEURITE GROWTH}

\section{MT Sliding in Neuritogenesis}

Microtubule sliding is essential for adding and removing MTs from neurites (Lu and Gelfand, 2017; Rao and Baas, 2018). It involves the rapid transport of short polymers (less than $10 \mu \mathrm{m}$ long) by kinesin-1 and dynein. Kinesin-1 based sliding drives the initial growth of a neurite from the cell body in a process called neurite initiation (Lu et al., 2013). The mechanism involves the coupling of anti-parallel MTs via the motor domain and a second MT binding domain located close to the C-terminus (Winding et al., 2016). As kinesin-1 walks toward the plus end of one MT, it slides the two MTs apart. While sliding is critical for initiation, its involvement in growth once axons reach a length greater than $10-50 \mu \mathrm{m}$ is less clear; it drops by 50 fold as axons extend over the course of $16 \mathrm{~h}$ in Drosophila ( $\mathrm{Lu}$ et al., 2013). One reason for this decline is that kinesin-1 based sliding appears to require that MT have an anti-parallel configuration, but axonal MTs are predominantly parallel (del Castillo et al., 2015b). Somewhat ironically, the generation of parallel arrays of MTs is mediated by dynein based sliding (del Castillo et al., 2015b; Rao and Baas, 2018). As the motor domain of dynein walks along short MTs, it pushes those that point with their plus end toward the cell body out of the axon. In addition to these changes in polarity, the length of MTs increases as axons mature (Figure 4). Because longer MTs have a higher probability of becoming crosslinked with the cytoskeletal array, sliding is also inhibited (Craig et al., 2017). Somewhat surprisingly, the best-characterized class of proteins that suppress MT sliding are the mitotic kinesins: kinesin-5, kinesin-6 (i.e., Pavarotti), and kinesin-12 (Lin et al., 2012; Del Castillo et al., 2015a; Rao and Baas, 2018). What they appear to have in common is that they bundle parallel arrays of MTs instead of driving motion. Bringing the ideas of MT polarity, length, and sliding together, a picture emerges that during the initial process of neurite initiation and outgrowth, MTs are short and often have an anti-parallel configuration. Together these allow robust sliding of short MTs that initially increases the number of MTs in the axon. Over time, dynein slides anti-parallel MTs out of the axon, MT length increases, proteins that suppress MT sliding are activated, and MT sliding declines.

Regarding the elongation that follows neuritogenesis, the contribution of MT sliding is less clear. While essentially no rapid sliding has been observed in Drosophila axons after this stage (Lu et al., 2013), there are many studies in vertebrate neurons reporting that it occurs in long axons (Wang and Brown, 2002; He et al., 2005); this includes our recent work where we analyzed MT motion using fluorescent speckle microscopy 
(Athamneh et al., 2017). As our interest is to quantify the contributions that multiple processes make to elongation, we reviewed the data from several key papers and compared it with our findings (Athamneh et al., 2017). This analysis suggested that MT sliding supports the addition of enough MTs to support the extension of the axon at a rate of a few microns per hour (Athamneh et al., 2017), yet axons often extend at much higher rates (i.e., $\sim 25 \mu \mathrm{m} / \mathrm{h}$ in our study). A caveat with this analysis is that a recent paper indicates that much higher levels of MT sliding can occur (Rao et al., 2017). Whether this is due to the use of better markers to track MT motion, the observation of tubulin transported by the endosomal pathway (Chang et al., 1999), or is a function of where and when transport is observed will require a more systematic analysis.

In contrast to MT sliding, analysis of bulk MT transport as we will discuss indicates that it can fully account for the forward movement of MTs needed for growth cone advance. An idea that we favor is that the force generating mechanisms that initially drive robust sliding during neuritogenesis are used to power bulk advance in growing axons (Roossien et al., 2014; Kahn and Baas, 2016). An essential future direction will be to extend the groundbreaking work on MT sliding to test the biophysical contributions of the mitotic kinesins, kinesin-1, and dynein in the mechanics of axonal elongation.

\section{Axons Elongate Through Bulk Transport of MTs}

Whether MTs move in bulk or are stationary relative to the substrate has been debated for roughly 40 years (Hoffman and Lasek, 1975; Bamburg et al., 1986; Baas, 1997; Hirokawa et al., 1997; O’Toole et al., 2008a). It stirs passions because it underlies our fundamental understanding of how axons elongate. While some of the earlier MT labeling studies showed clear evidence of MT translocation during axonal elongation (Reinsch et al., 1991), others did not (Lim et al., 1990; Okabe and Hirokawa, 1990). Roughly a decade ago, while investigating fast mitochondrial transport (Miller and Sheetz, 2004), one of the co-authors noted that 'docked' mitochondria, i.e., stably bound to MTs, actin filaments, and neurofilaments (Sheng and Cai, 2012), were not stationary relative to the substrate. Using kymographs to track their motion over long periods indicated that they moved in a coherent manner consistent with bulk MT flow (Miller and Sheetz, 2006). To test if mitochondria move through or with the axon, the motion of beads bound to the outside of the axon and axonal branch points were tracked (Lamoureux et al., 2010). As beads and branch points moved in a pattern similar to mitochondria, this suggested that the cytoskeletal framework moved forward as a whole. In parallel, studies in Aplysia growth cones indicated that MTs also undergo forward translocation in the growth cone central domain during adhesion-mediated neurite advance (Lee and Suter, 2008; Schaefer et al., 2008). Quite strikingly, while the prevalent model was that MT assembly drove elongation, $80 \%$ of the advance of MTs was accounted for by translocation. To test if bulk motion was an artifact of tissue culture, docked mitochondria were followed in vivo in intact Drosophila embryos. As seen in vitro, they advanced in tandem with the growth cone (Roossien et al., 2013). While these different approaches in several model systems suggested that bulk MT motion accounts for elongation, they were in part indirect: docked mitochondria are not MTs, and the advance of MTs in response to a bead attached to the surface of a growth cone does not reflect axonal elongation. The critical experiment to directly track the bulk motion of MTs in freely growing neurites using fluorescent speckle microscopy was needed to test that hypothesis that bulk MT motion accounted for axonal elongation.

To address this question, the co-authors recently collaborated to track the motion of docked mitochondria, MTs, and the overall motion of cytoplasmic material in both rapidly growing chick and Aplysia neurites (Athamneh et al., 2017). This study intended to answer several critical questions: (1) What is the relationship between MT translocation, MT assembly, and neurite elongation; (2) Is the fundamental process of axonal elongation conserved between species? Moreover, (3) is the motion of docked mitochondria a reliable marker for the motion of MTs? The clear answers from these experiments were that MTs advance in bulk at the same average rate as growth cones, the process of elongation is highly conserved, and the bulk motion of docked mitochondria and MTs is highly correlated.

\section{Does MT Advance Drive Axonal Elongation?}

The strong correlation between bulk MT transport and axonal elongation raises the question of whether bulk MT transport drives elongation. One of the authors' recent in vitro study in Aplysia growth cones provides insights into this problem and addresses the question of why Aplysia growth cones are much larger than those of other species (Ren and Suter, 2016). When Aplysia neurons are plated on poly-L-lysine-coated coverslips, they initially extend several short neurites that have relatively small growth cones, which rapidly expand to the well-known large fan-shaped growth cones of $100 \mu \mathrm{m}$ in diameter (Figure 5). After the initial process of extension, the leading edge of the growth cone slowly advances at a rate of $1-5 \mu \mathrm{m} / \mathrm{h}$, but the neck of the growth cone stays in position. At this point, growth cone advance mainly reflects an increase in the size of the growth cone rather than translocation. Over time, the width of the axon is relatively constant, but the growth cone becomes dramatically larger (Figure 5). Based on the change of growth cone area, a large amount of cytoskeletal and organelle mass is being added to the growth cone with only little net advance. Although MTs were not imaged in this study, it has previously been shown that both MT assembly and forward translocation occur in these large growth cones that exhibit minimal net advance (Schaefer et al., 2002; Lee and Suter, 2008). This phenomenon is not unique to Aplysia. When Xenopus growth cones rapidly advance, MTs translocate forward, there are relatively few MTs in the growth cone, and they tend to be splayed. When growth cones pause spontaneously, bulk MTs advance continues, and this is paired with MT looping and accumulation (Tanaka and Kirschner, 1991; Tanaka et al., 1995). Likewise, in chick sensory neurons when growth cones pause either spontaneously or when the growth cone is held in 

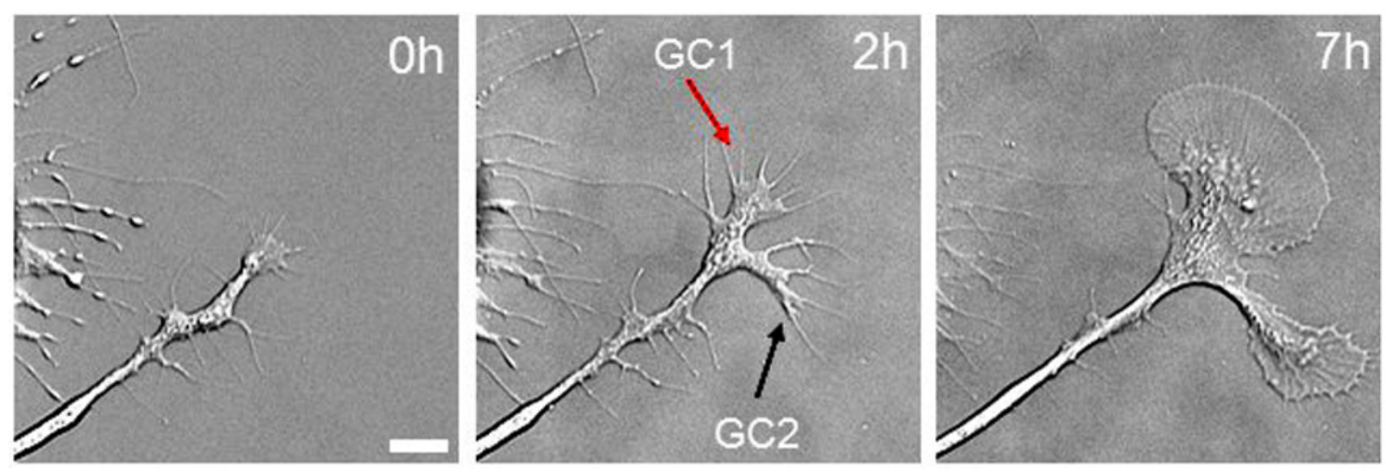

FIGURE 5 | Mass addition to the growth cone does not drive axonal elongation. Differential interference contrast images of Aplysia bag cell neuronal growth cone immediately after cell plating (left), $2 \mathrm{~h}$ later (middle), and $7 \mathrm{~h}$ later (right). Scale bar: $10 \mathrm{~m} \mu \mathrm{m}$. Reprinted from Ren and Suter (2016) with permission from Hindawi.

position using a towing needle, a dramatic increase in the number of mitochondria in the growth cone occurs as the result of bulk translocation (Miller and Sheetz, 2006; O’Toole et al., 2015). The observation that bulk transport occurs during growth cone pauses suggests it does not drive elongation. In doing so, these observations raise the question, 'What is the relationship between bulk transport and elongation?'

In our fluorescent speckle microscopy analysis of MT motion, we found that on average there is a one to one correlation between bulk MT transport and the average rate of growth cone advance (Athamneh et al., 2017). Nonetheless, we do not interpret this correlation as indicating that bulk transport causes elongation. Looking at the regression of axonal MT velocity and growth cone velocity in both chick and Aplysia neurons (Athamneh et al., 2017), the rates of bulk advance only rarely matches the rate of growth cone advance over 10-min intervals. For example, there are cases where the growth cone is stationary, but bulk advance occurs at $25 \mu \mathrm{m} / \mathrm{h}$; likewise, there are equal numbers of cases where the converse occurs. As growth cone velocity is characterized by alternating periods of retractions, pauses, and advances, a picture emerges that growth cones go through cycles, where they rapidly advance, deplete the material in the growth cone and relieve compression on MTs. When pauses occur, material accumulates, and MT compression occurs (Rauch et al., 2013). This suggests that the primary role of bulk transport is delivering material to the growth cone. While this is likely a critical step in the cycle needed for sustained outgrowth, the process of growth cone advance over short timescales appears to be more tightly linked to whether the transition zone and peripheral domain move forward. In the next section, we develop a biophysical understanding of elongation that considers the interplay between forces generated by actin, MTs, and the plasma membrane that control this process.

\section{FORCE AND MOTION}

\section{The Biophysical Properties of Neurons}

Understanding neurite outgrowth requires a detailed knowledge of the biophysical properties of neurons
(Suter and Miller, 2011; Franze et al., 2013). Neurons from different species significantly differ in their biophysical properties and levels of force production, respectively (Spedden and Staii, 2013; Athamneh and Suter, 2015). Several approaches have been developed to measure elasticity, viscosity, and force generation in neurons. Particularly valuable tools have been glass microneedles (Bray, 1984; Lamoureux et al., 1989; Suter et al., 1998; Bernal et al., 2007; Athamneh et al., 2015; O’Toole et al., 2015) and more recently microelectromechanical (MEMs)-based force sensors (Siechen et al., 2009; Rajagopalan and Saif, 2011). Typically their bending constants or stiffness values are determined first (Lamoureux et al., 2011), and then forces are measured and applied by optically measuring the amount of bending and controlling their position. Complementing these are innovative approaches using atomic force microscopy (Xiong et al., 2009; Betz et al., 2011; Athamneh et al., 2015), magnetic tweezers (Kilinc et al., 2014; Grevesse et al., 2015), fluid flow (Bernal et al., 2010), vibration of the axon (Garate et al., 2018), FRET-based fluorescent force sensors (Krieg et al., 2014), traction force microscopy (Chan and Odde, 2008; Koch et al., 2012), and laser tweezers (Cojoc et al., 2007; Shahapure et al., 2010; Amin et al., 2013). With these techniques, it is well established that axons behave as solid-like materials in response to transient forces applied for less than $10 \mathrm{~s}$ (Bernal et al., 2007; Betz et al., 2011), yet as fluids in response to constant forces applied for tens of minutes (Zheng et al., 1991; O’Toole et al., 2008a, 2015). Depending on the type of neuron, axons generate a net tension between 0.5 and $4 \mathrm{nN}$ (Athamneh and Suter, 2015) that requires actin, ATP expenditure, and myosin activity (Dennerll et al., 1988; Lamoureux et al., 1989; Bernal et al., 2007; Tofangchi et al., 2016). Balancing contraction by actomyosin, MTs bear compressive forces which may be generated in part by dynein (Dennerll et al., 1988; Roossien et al., 2014) and MT assembly (Figure 6). While detailed measurements are essential for quantifying neuronal mechanics, it is equally important to have a theoretical framework to place these observations into context. For example, if one views neurons as solid-like materials, while constant forces generate 'pre-stress', they do not lead to continuous motion needed to account for bulk MT motion. Likewise, simple fluid-like models of neurons fail to capture 


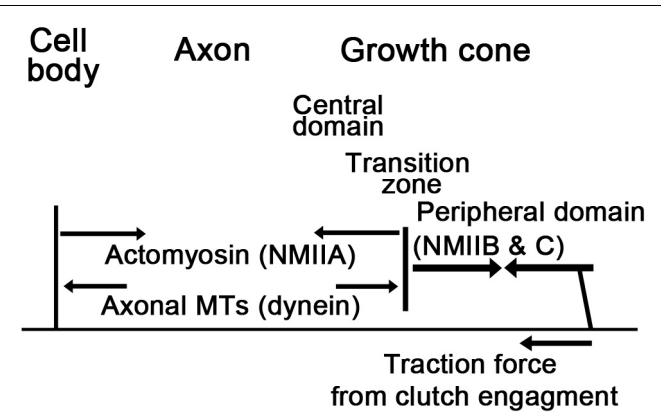

FIGURE 6 | Neuronal force balance. Strong contractile forces by NMIIB and NMIIC at the leading edge pull the transition zone and central domain forward. These forces are countered by NMIIA in the axon and assisted by extensile forces generated through dynein mediated sliding of MTs and MT assembly. Axonal elongation occurs when the traction forces that pull the transition zone forward are higher than the net contractile forces generated in the axon. Arrows represent forces.

the solid-like behavior of neurons needed to understand injury arising from a traumatic impact. Reconciling the paradoxical behaviors of neurons requires the adoption of more sophisticated models that are at the cutting edge of soft matter physics.

\section{Are Neurons Active Fluids?}

The mechanical behavior of cells is controlled by structures and processes that are far from thermodynamic equilibrium (Prost et al., 2015). While the study of such systems once was beyond the bounds of conventional physics, a new field has emerged called active gel or active matter physics that considers the influence of internal force generation on mechanics (Marchetti et al., 2013). The unique properties of active matter systems are that they spontaneously generate motion and re-organization of the material. While our focus is on the neuronal cytoskeleton, the theory developed in this field is relevant to flocking, vibrating granules, and microorganisms in suspension (Kumar et al., 2014; Lopez et al., 2015). The mathematics that describes active fluids are complex as they are typically expressed using tensor calculus and consider changes in local orientation, thermodynamics, stress, strain, and motion over time and space (Marchetti et al., 2013; Prost et al., 2015). To explain active matter modeling of the cytoskeleton simply in words, the working assumptions are that it is a Maxwell fluid, similar to Silly Putty, which contains 'force dipoles' (i.e., motors that can pull material together and/or push it apart) (Callan-Jones and Julicher, 2011; Prost et al., 2015). When the cytoskeletal elements are aligned, long-distance gradients in stress and motion occur over space and time. Building on this, one of the co-authors have described axons as active Maxwell fluids with the equation (Eq. 1),

$$
\dot{\varepsilon}=\frac{\sigma_{\text {Ext }}+\sigma_{\text {Int }}}{\eta}+\frac{\dot{\sigma}_{\text {Ext }}+\dot{\sigma}_{\text {Int }}}{E} ; \eta=E \tau
$$

where the strain rate $(\dot{\varepsilon})$ is equal to the constant stress $(\sigma=$ force / area) arising from both external and external sources divided by viscosity $(\eta)$, plus the change in stress over time $(\dot{\sigma})$ divided by the Young's modulus (E) (de Rooij et al., 2017). Importantly, viscosity and elasticity are related by a time constant $(\tau)$ which is in the range of seconds to minutes in cells (Julicher et al., 2007; Betz et al., 2011; Purohit, 2015). Over periods significantly shorter than $\tau$ cells behave like solids, while at longer times they act as fluids (O’Toole et al., 2015).

A concrete way to imagine the cytoskeleton as an active Maxwell fluid is to consider it as a system of rods that are highly cross-linked by dynamic springs (de Rooij et al., 2017). $\tau$ is related to the $K_{\text {on }}$ and $K_{\text {off }}$ rates that describe the binding and unbinding of the cross-links, $E$ is related to the spring constants of the cross-linkers and rods, and viscosity is an emergent property. By emergent property, we mean that the system is at a given time point a solid with a modulus of $E$, but flows as a fluid because the cross-links are dynamic as described by $\tau$. When the system is under stress, motion occurs because the unbinding and rebinding of cross-linkers dissipates energy and gives rise to 'permanent' deformation. In turn, the generation of internal forces by motors occurs by linking ATP consumption to the shortening of crosslinked springs. In essence, when a motor undergoes a power stroke, it is converted from a long to a short spring (de Rooij et al., 2017). This length change generates tension, which pulls materials together.

The utility of a model is based on how well it reflects observed behavior. This raises the question 'Do axons behave as active Maxwell fluids?' There are several lines of evidence that suggest so. Bernal's group (Bernal et al., 2007) demonstrated that over short times $(<10 \mathrm{~s})$, axons behave like solids and actively generate forces. In contrast over minutes to hours, there is a steady rate of actin retrograde flow in the growth cone (Betz et al., 2011) coupled with a continuous bulk forward advance of material along the axon (O'Toole et al., 2015; Athamneh et al., 2017). The study by Betz et al. (2011) is notable in that it was the first to apply principles of active fluids to understand growth cone mechanics. We also would like to highlight the application of these principles for modeling the retrograde flow of Aplysia growth cones (Craig et al., 2012) and bulk motion during neurite outgrowth (O'Toole et al., 2008a; Recho et al., 2016).

While there is broad agreement that actin in the growth cone is an active fluid (Betz et al., 2011; Craig et al., 2012; Recho et al., 2016), whether axonal MTs are as well has a more complicated history. In the first well-articulated biophysical model for axonal elongation (Dennerll et al., 1989), axonal MTs where modeled as a viscoelastic solid (i.e., a spring in series with a spring and dashpot in parallel), capped with a fluid-like dashpot at the growth cone. While this system as a whole is a viscoelastic fluid, the axon was considered a viscoelastic solid. The justification for this arose from suggestions that MTs are stationary along the axon, while new MTs are dynamically assembled and disassembled in response to forces at the growth cone (Bamburg et al., 1986; Heidemann, 1990). While there have been numerous models that treat axons as solids, typically referencing (Dennerll et al., 1989), more recent studies suggest that axons internally stretch like a fluid (O'Toole et al., 2008a, 2015). This idea is supported by the fact that mixtures of MTs and kinesin behave as active fluids (Wu et al., 2017), MTs slide as single filaments (Lu and Gelfand, 2017; Rao and Baas, 2018), axons take up slack (Tofangchi et al., 2016), and growth cone retracts back to the cell body in a fluid-like 
manner when adhesion to the substrate is disrupted ( $\mathrm{O}^{\prime}$ Toole et al., 2015). To put this shifting view of axonal mechanics in perspective, while two of the founders of the field of neuronal mechanics, Dennis Bray and Steven Heidemann, once favored the idea of a solid-like axon, they now support the view they are fluid-like structures (Heidemann and Bray, 2015). In summary, the available evidence strongly indicates that axons and the MT arrays contained within them act as fluids during the process of neurite outgrowth. By adopting a model of neurons as active Maxwell fluids, the study of axonal elongation can advance to a state where the relative contributions of diverse mechanisms, over a broad range of time scales, can be considered and related in a unified model (de Rooij et al., 2017, 2018; de Rooij and Kuhl, 2018).

\section{Forces in Series}

A major challenge in cell mechanics is relating specific force measurements, typically made by probing the outside of cells, with the profile of subcellular force generation within a cell (Park et al., 2010; Canovic et al., 2014). Whereas it is intuitive that parallel forces sum (e.g., consider two people pushing a box), how forces combine in series as is the case of an axon attached to a growth cone, is rarely discussed. It is well documented that neurons generate traction forces on the order of $1 \mathrm{nN}$, and it is typically assumed that growth cones are the primary site of force generation. However, does this mean that growth cones generate $1 \mathrm{nN}$ of force? To better understand this, one the co-authors systemically considered the problem of how forces interact in series (O'Toole et al., 2015). Without going into the details of its derivation, the equation that describes the relationship between net force and the forces generated in the axon and growth cone is given by Eq. 2 .

$$
F_{\mathrm{Net}}=F_{\mathrm{GC}} \frac{\eta_{\text {Axon }}}{\eta_{\mathrm{GC}}+\eta_{\mathrm{Axon}}}+F_{\mathrm{Axon}} \frac{\eta_{\mathrm{GC}}}{\eta_{\mathrm{GC}}+\eta_{\mathrm{Axon}}} .
$$

Here, we have a model where the neuron has two compartments that can have different viscosities $(\eta)$ and levels of internal force generation $(F)$. On one end, the axon is attached to a fixed point, and on the other, the growth cone is affixed to a means to measure net force. If we assume for the moment that the viscosity in both regions is the same, the net force is equal to the average force. For example, if forces were only generated in the growth cone, the net force would be equal to half of that. An intuitive explanation for why this occurs is that when no forces are generated in the axon, contraction occurs in the growth cone. Since this motion is coupled with the dissipation of forces through viscosity, the force measured externally is reduced. This equation implies that the measured net force provides little information about the site and magnitude of internal force generation; just because a growth cone pulls on the substrate, does not mean it is the primary site of force generation.

The theory outlined in Eq. 2 lead us to ask where are forces generated in neurons and what is their magnitude. In thinking about neurons are active fluids, it became clear that when the local internal forces are equal to the external forces, the local region neither expands or contracts (O’Toole et al., 2015). Using towing needles attached to the growth cone to systematically vary the external force while monitoring subcellular strain rate by tracking docked mitochondria, we found the contractile force across the central domain to be $2 \mathrm{nN}$, while along the axon it was $0.6 \mathrm{nN}$. In turn, the average net force for the chick sensory neuron as a whole was $1.3 \mathrm{nN}$. Because the net force was close to the average of the forces in the two regions, this suggests the viscosity of the rear of the growth cone (which contains MTs in the central domain surrounded by actin arcs) is similar to the viscosity of the axon (which is composed of axonal MTs surrounded by an actin cortex) (Figure 2B). In addition, it makes clear that the traction forces measured at the growth cone (Chan and Odde, 2008; Koch et al., 2012) are a complex function of the subcellular profile of force generation (Figure 6).

The second implication of this model is that net traction forces generated by neurons are likely independent of the whether axons elongate or not. Combining Eqs. 1 and 2, the rate the axon lengthens is determined by the difference in forces generated in the growth cone and axon, divided by the viscosity of the axon. While fast elongation could be paired with high levels of force generation in the growth cone as the result of clutch engagement, it could also result from low levels of force generation in the axon (Figure 2). The study by Hyland looked carefully at the correlation between net traction force and the rate of elongation (Hyland et al., 2014). They found, in essence, no strong correlation and noted that the highest traction forces were often generated by the slowest growing neurons. As we will develop below, we think the reason for this is that Rho selectively leads to the activation of NMIIA along the axon, which generates a contractile force that opposes growth cone advance (Figures 2C, 6). This suggests that it is more critical to consider the subcellular pattern of force generation rather than the total force. In discussing these results, Hyland et al. (2014) pointed out that it was paradoxical that there was no strong correlation between traction forces and outgrowth rate, yet there is a strong correlation between externally applied forces and elongation. Based on one of the author's recent modeling study (de Rooij et al., 2018), we think a possible explanation is that external forces directly cause the axon to stretch or contract as a compartment. In contrast, in neuronal cultures traction force arises from the balance of forces between the axon and growth cone. Thus, higher traction forces do not necessarily equate to faster elongation (Figure 6).

In conclusion, a key determinate of whether axons elongate, stall or retract appears to be the gradient in the force profile from the axon across the growth cone (Figure 2C). When the levels of force generation in the axon and growth cone are similar, high traction forces will be produced, but the material will not flow forward. In turn, if the level of contractile forces is higher in the axon than in the growth cone, retraction occurs. Only when the levels of force generation are higher in the growth cone than the axon, material flows forward (Figure 6). A secondary and related idea is that viscosity controls the rate of material flow (O'Toole et al., 2008a). In general, changes that decrease viscosity without altering forces will lead to faster rates of elongation and retraction, whereas inhibiting the dynamics of 
cytoskeletal elements or increasing the number or the stability of cross-linkers will have the reverse effect (de Rooij et al., 2017, 2018).

\section{Axons Elongate at the Rate of Transition Zone Advance}

With this background on neurons as active materials in mind, we can now return to the question of the relationship between bulk MT transport and growth cone advance. Combining estimates of subcellular forces generation (O'Toole et al., 2015) with a detailed analysis of MT motion in growing neurites (Athamneh et al., 2017) provides a comprehensive picture of subcellular force generation and motion (Figures 2C,E). Far from the growth cone ( $>200 \mu \mathrm{m}$ ), MTs are stationary relative to the substrate (Miller and Sheetz, 2006). In the growth cone, MT translocation velocity rises to an average rate of $\sim 25 \mu \mathrm{m} / \mathrm{h}$ (Athamneh et al., 2017). This gradient in velocity reflects the stretching of the axon. It is caused by the difference in contractile forces between the axon and the traction forces generated in the growth cone and shaped by the frictional interactions between the axon and substrate (O'Toole et al., 2008a; Figure 2D). Across the growth cone, MT velocity drops sharply, to a large negative value of $\sim-125 \mu \mathrm{m} / \mathrm{h}$ over a region of $\sim 5-10 \mu \mathrm{m}$ in the peripheral domain (Athamneh et al., 2017). The switch from slow bulk anterograde motion to rapid retrograde flow occurs at the transition zone when MTs enter into the peripheral domain and become coupled with retrograde actin flow (Schaefer et al., 2002, 2008; Lee and Suter, 2008). As the growth cone advances over time, this profile moves forward in space at a rate roughly equal to a peak rate of MT advance in the growth cone (Athamneh et al., 2017).

While, we measure velocity in one dimension, axons are threedimensional, and volume is conserved during rapid stretching (Fan et al., 2017). If we ignore for the moment the delivery of material through fast and slow axonal transport, changes in velocity along the axis of the axon are paired with alterations in diameter. In regions where the velocity gradient is positive (i.e., it increases with distance from the cell body) 'stretching' occurs and diameter decreases, likewise in the growth cone where the velocity gradient is negative diameter increases. Mechanically, this explains in part why growth cones are wide, and axons are thin. Strikingly, if new materials were not added to axons, they would rapidly thin behind the growth cone (O'Toole et al., 2008a).

Nonetheless, neurons are not passive materials: the subcellular assembly and disassembly of MTs are tightly controlled. Because axonal diameter remains relatively constant during elongation (Bray, 1984), fast axonal transport of organelles, slow axonal transport of cytoskeletal elements, and net MT assembly are needed to maintain axonal diameter (O'Toole et al., 2008b). In support of this, the flux associated with transport declines along the axon, which adds mass (Miller and Samuels, 1997; O'Toole and Miller, 2011). Paired with this, analysis of end-binding (EB) $1 / 3$ protein comets and markers for MT dynamics indicates that MT assembly occurs preferentially in the distal axon, where stretching is most prominent (Baas and Black, 1990; Cammarata et al., 2016; Qiang et al., 2018). Thus, while our recent quantitative analysis of MT motion indicates that axons do not advance by the assembly of MTs at the tip of the central domain (Athamneh et al., 2017), analysis of the velocity gradients suggests robust assembly is needed in the distal axon to prevent thinning. The observation of robust MT assembly in the distal axon raises the question, 'why doesn't MT assembly at tip drive elongation.' One possibility is that when MTs extend into the peripheral domain, they come under high stress, which bends and breaks the plus ends off (Schaefer et al., 2002, 2008; Lee and Suter, 2008; Rauch et al., 2013). In turn, MT disassembly may occur (Tang-Schomer et al., 2010). Thus, the same MTs that could add mass at the tip of the central domain are the ones most likely to depolymerize.

Based on these considerations, we propose that the transition point, where the velocity gradient shifts from positive to negative (Figure 2E), regulates the shape and size of the growth cone (Figure 5). Behind this point, axonal thinning occurs because of stretching. In front of this point, thickening occurs through contraction. When the growth cone pauses, this transition point shifts back toward the contractile node in the neck of the growth cone, which leads to the widening of the central domain because contraction pushes material outwards. In contrast, during rapid elongation, this point shifts forward toward the actin-rich region in front of the growth cone, which causes the central domain to stretch and decrease in width. As the transition zone and actin arcs surrounding the sides of the growth cone are critical for creating this velocity gradient, the question of what controls its advance becomes critical for understanding elongation. As we develop next, the net forces generated by multiple sources including membrane tension, MTs assembly, axonal contraction, actin retrograde flow, and clutch engagement are integrated into a net force vector across the transition zone that controls its advance (Figures 2, 6). In terms of the biology, a critical question is the relative force contributions of each of these mechanisms.

\section{Does MT Assembly Create a Pushing Force That Drives Elongation?}

The observed correlation between bulk MT advance and elongation (Athamneh et al., 2017) challenges the idea that new tubulin addition at the tip is the main driving force for neurite elongation. To determine if MT assembly modulates bulk transport, we disrupted it and tracked bulk motion (Athamneh et al., 2017). Strikingly, this blocked forward advance, lead to retraction of material in the distal axon, and increased tension by roughly $60 \%$. Collectively this suggests that normal MT assembly is needed for elongation because when it is disrupted, tension rises (presumably along the axon) that pulls material rearward. While models of axonal elongation have suggested that MT assembly generates a pushing force that drives elongation (Buxbaum and Heidemann, 1992; Recho et al., 2016), we suspect that the large compressive forces created by MTs are primarily generated as the result of MT sliding by motors and coupling between MTs and actin retrograde flow via cross-linkers. For MT assembly to generate a significant pushing force, it must be stalled against a barrier (Dogterom and Yurke, 1997). In agreement with this, EB3-GFP comets do not stall along the 
axon (Stepanova et al., 2010), as they would if they were pushing against a barrier. In addition, as the stall force of a MT is $\sim 5 \mathrm{pN}$ (Dogterom and Yurke, 1997) and the numbers of MTs in a typical growth cone are in the range of $5-20$, the force generated by assembly is theoretically small compared to the net forces generated by NMII and dynein that act on MTs (Koch et al., 2012; Roossien et al., 2014). If we exclude the idea that MT assembly generates large extensile forces, why does tension rise so dramatically when assembly is blocked? Here, we see two untested but logical possibilities. The first is that disruption of MT assembly interferes with the ability of dynein to generate large extensile forces which have been measured to be at least $400 \mathrm{pN}$ in sensory neurons (Roossien et al., 2014). As dynein is a +tip protein (Duellberg et al., 2014) and drugs that target MT dynamics lead to disassociation of + tip proteins from MTs (Morrison et al., 1998), disruption of MT assembly could dramatically reduce the ability of dynein to generate extensile forces on MT arrays (de Rooij et al., 2017). Secondly, disruption of MT assembly could lead to the activation of NMII along the axon via the GEF-H1 - Rho signaling pathway (Chang et al., 2008; Takano et al., 2017; de Rooij and Kuhl, 2018). While the idea that MT assembly generates a pushing force that drives elongation has been an attractive one, we believe that there are plausible alternative hypotheses, which in our eyes need to be tested.

\section{Is the Growth Cone a Battering Ram?}

Cajal initially compared the growth cone with "a living battering ram, soft and flexible, which advances, pushing aside mechanically the obstacles which it finds in its path" (Ramón y Cajal, 1995). This evokes an impression that it pushes forward with large forces. Consistent with this idea actin filaments polymerize at the leading edge (Forscher and Smith, 1988), and their assembly generates a force of 5-10 pN per filament in vitro (Greene et al., 2009; Figure 2). As there are 100-200 actin filaments per micron at the leading edge of cells (Koestler et al., 2008), a $1 \mu \mathrm{m}$ region could generate as much as $\sim 1 \mathrm{nN} / \mu \mathrm{m}$. Furthermore, in non-neuronal cells, the forward pushing force of the lamellipodia has been directly measured using atomic force microscopy to have a stall force of roughly $0.3 \mathrm{nN} / \mu \mathrm{m}$ (Prass et al., 2006). Similarly, using a more refined analysis, the pushing force associated with actin assembly in the lamellipodia of Aplysia neurons has been estimated theoretically to be $\sim 100 \mathrm{pN} / \mu \mathrm{m}$ (Craig et al., 2012). As the length of the leading lamellipodial edge in a typical chick sensory growth cone is $\sim 5-10 \mu \mathrm{m}$, these growth cones could theoretically push forward with $0.5-1 \mathrm{nN}$ of force. This is similar to the pulling or traction force, $\sim 1.5 \mathrm{nN}$, of these growth cones (Athamneh and Suter, 2015; O'Toole et al., 2015).

In contrast to theory, experimental data suggest that the forward pushing force of actin assembly in growth cones is extraordinarily small. When the pushing force of growth cones was measured directly in sensory or hippocampal neurons, individual filopodia pushed forward with $\sim 1-5 \mathrm{pN}$ and the lamellipodia with $\sim 10-20 \mathrm{pN} / \mu \mathrm{m}$ (Cojoc et al., 2007; Amin et al., 2013). If we assume that the length of the leading edge of a growth cone is $10 \mu \mathrm{m}$, the net force would be $100 \mathrm{pN}$; roughly 10 times less than the traction forces (O'Toole et al., 2015). One possibility to explain these small forces is that membrane tension is very high and most of the forces associated with actin assembly are directed to pushing it forward. Yet, the in-plane membrane tension in chick sensory and $C$. elegans neurons are $3 \mathrm{pN} / \mu \mathrm{m}$ and $\sim 12 \mathrm{pN} / \mu \mathrm{m}$, respectively (Hochmuth et al., 1996; Krieg et al., 2014). This suggests that the small measured pushing force of growth cones does not arise because large forces that counteract each other. Instead, membrane tension and the force of actin polymerization are both small and balanced. This is consistent with the idea that membrane tension may be determined by the tension at which actin polymerization underneath the membrane is mechanically stalled (Sens and Plastino, 2015). Regarding growth cone behavior, the close balance between these forces has also been suggested to account for the probabilistic anterograde and retrograde motion of the growth cone (Shahapure et al., 2010). While membrane addition is critical for the process of axonal elongation and blocking membrane addition halts elongation (Quiroga et al., 2018), membrane tension does not appear to be significantly limit the assembly of actin or the advance of the growth cone through large forces.

\section{Substrate-Cytoskeletal Coupling}

In addition to pushing forward, most types of growth cones generate pulling or traction forces in the range of 0.5 to $3 \mathrm{nN}$ (Athamneh and Suter, 2015). Neuronal cell lines and central nervous system neurons generate forces at the lower end of the range, whereas peripheral nervous system neurons build up moderate forces. An exception is the enormous growth cones of Aplysia neurons, which can develop traction forces up to 100 $\mathrm{nN}$ (Athamneh et al., 2015). Strikingly, single filopodia in chick sensory neurons can pull with a force of $\sim 1 \mathrm{nN}$ (Heidemann et al., 1990; Bridgman et al., 2001) suggesting that forces in the growth cone can be highly directed. Nonetheless more typically, traction force analysis indicates that forces are distributed over the growth cones, with a few peaks of high intensity (Koch et al., 2012; Hyland et al., 2014; Figure 2D). How do retrograde traction forces in the growth cone develop, and what is their function?

The substrate-cytoskeletal coupling model explains the generation of traction forces by proposing that point contacts link actin undergoing retrograde flow to the extracellular matrix (Suter et al., 1998; Bard et al., 2008; Shimada et al., 2008; Nichol et al., 2016). Engagement of the clutch through linkages between the actin cytoskeleton and the adhesion receptors, through proteins such as talin, vinculin, shootin1, and cortactin (Toriyama et al., 2013; Gomez and Letourneau, 2014; Kubo et al., 2015) increases traction forces and slows flow (Figures 2, 6). Relatively little is known how guidance cues and signaling affect force production in growth cones and neurites. The few studies that have published in this area focused on how signaling regulates clutch formation and thereby traction force. The Inagaki group has shown that netrin1 causes Pak1-mediated shootin1 phosphorylation to regulate substrate-cytoskeletal coupling and traction force production 
(Toriyama et al., 2013). Phosphorylation is probably the most common post-translational protein modification associated with force production. Along these lines, Suter and Forscher have shown that strong coupling between the cell adhesion molecule apCAM and actin cytoskeleton in Aplysia growth cones depends on Src-mediated tyrosine-phosphorylation (Suter and Forscher, 2001).

How substrate-cytoskeletal coupling translates into growth cone advance is not fully understood. A classic interpretation of the clutch hypothesis is that it reduces the rate of retrograde actin flow, and increases the rate of growth cone advance (Mitchison and Kirschner, 1988; Suter et al., 1998; Suter and Forscher, 2000). The reduced actin flow consequently represents a reduced barrier to MT assembly into the peripheral domain (Hur et al., 2011; Cammarata et al., 2016; Blanquie and Bradke, 2018). Whereas there have been several reported examples where the growth cone transition from one substrate to another resulted in an inverse relationship between actin flow and growth cone advance (Lin and Forscher, 1995; Suter et al., 1998; Nichol et al., 2016), slower rates of retrograde flow are not always linked to faster elongation. For example, when Aplysia growth cones are treated with serotonin (i.e., 5-HT) both retrograde flow and elongation increase (Zhang et al., 2012). Disruption of NMII with blebbistatin reduces traction forces, retrograde flow, and elongation when neurons are grown on laminin (Medeiros et al., 2006; Ketschek et al., 2007; Koch et al., 2012). Inhibition of actin disassembly reduces retrograde flow, traction forces and elongation (Gallo et al., 2002; Van Goor et al., 2012; Hyland et al., 2014). Finally, when we examined the correlation between retrograde flow and axonal elongation, flow rates increased as the rate of elongation rose (Athamneh et al., 2017). In light of these findings, we believe that the primary function of the clutch is not to reduce actin flow, but rather to increase the tension between adhesions and the transition zone (Figure 2). When this causes the net force vector over the transition zone to be positive, the transition zone advances and MTs flow forward in bulk.

A general prediction of this model is that higher rates of elongation should be paired with higher traction forces. In support of this, it is well established that traction forces and elongation rise when the clutch is engaged (Suter et al., 1998; Athamneh et al., 2015; Kubo et al., 2015). Nonetheless, a careful analysis of growth rates and traction forces in freely growing neurons indicates forces and growth rate are not correlated (Hyland et al., 2014). As we indicated above and will develop in the next sections, the growth cone is not the only source of force generation in neurons. In addition, contractile forces are generated along the axon (O'Toole et al., 2015; Tofangchi et al., 2016) that could oppose the advance of the transition zone (Figures 2, 6). Furthermore, extensile force generation by the MT cytoskeletal is posed to decrease traction forces and boast elongation (Roossien et al., 2014). This suggests that axonal elongation is not controlled by a single process, but rather how multiple mechanisms interact (Figure 2). Through the next sections of the paper, we expand on the ideas introduced here to develop a more detailed understanding of the contribution of NMII, actin turnover, and actin-MT coupling in elongation.

\section{Force Generation by Non-muscle Myosin II in the Growth Cone}

Non-muscle myosin II has a central role in modulating axonal elongation and neuronal mechanics. It acts downstream of the major classes of guidance cues and signaling pathways including Slit, Netrin-1, Semaphorin-3A, Ephrin-A5, Rho and ROCK (Wahl et al., 2000; Wylie and Chantler, 2003; Gallo, 2006; Brown et al., 2009; Murray et al., 2010). Consistent with this role, it produces the majority of traction forces generated by neurons (Bridgman et al., 2001; Koch et al., 2012). Strikingly, while NMII generates large forces, it is not required for axonal elongation per se. Treatment of chick sensory neurons with $50 \mu \mathrm{M}$ blebbistatin, which reduces both NMIIA and NMIIB activity by $>95 \%$ (Limouze et al., 2004), only decreases the rate of axonal elongation on laminin by $66 \%$, and increases the rate on poly-lysine by $\sim 50 \%$ (Ketschek et al., 2007). Furthermore, disruption of NMII only slows retrograde flow by $50 \%$ in Aplysia growth cones (Medeiros et al., 2006). These observations suggest that while NMII generates large forces, there are other motors and force-generating mechanisms which power outgrowth in its absence. Instead, the primary role of NMII appears to be the modulation of outgrowth downstream of guidance cues.

A key to understanding the complex function of NMII is that there are three isoforms, NMIIA, NMIIB, and NMIIC, all of which are expressed at relatively high levels in the brain and each with specific, yet overlapping functions (Golomb et al., 2004; Wylie and Chantler, 2008; Shutova and Svitkina, 2018). Of note, disruption of NMIIB or NMIIC slows neurite elongation for N2A cells grown on fibronectin, while disruption of NMIIA increases it (Wylie and Chantler, 2001). More generally, NMIIA is recognized as promoting axonal retraction, while NMIIB drives elongation (Bridgman et al., 2001; Kubo et al., 2008; Wang et al., 2017). While all three are found in the growth cone, axon shaft, and cell body, there are variations in their peak levels of localization. NMIIA is found to be most concentrated along the axon shaft and central domain (Rochlin et al., 1995; Bridgman, 2002; Wylie and Chantler, 2008), whereas NMIIB and NMIIC are enriched in the transition zone (Rochlin et al., 1995; Wylie and Chantler, 2008; Figures 2C, 6). In turn, treatment of neurons with Semaphorin $3 \mathrm{~A}$, which causes growth cone collapse and retraction, increases the concentration of NMIIA in the axon and shifts NMIIB from the transition zone in front of the central domain to the neck of the growth cone (Gallo, 2006; Brown et al., 2009). Activation of Rho, which preferentially activates NMIIA in neurons (Kubo et al., 2008), drives contraction in the axon but does not affect retrograde flow (Zhang et al., 2003). Thus, a picture emerges that during rapid elongation NMIIB generates contractile forces in the growth cone to promote elongation, while NMIIA generates contractile forces along the axon that oppose it (Figure 6). From these observations, during slow growth or retraction, Rho is activated, which generates contractile 
forces along the axon mediated primarily by NMIIA. When Rho is inactive, contractile forces in the axon decrease, strong pulling forces generated by NMIIB (and perhaps NMIIC) in front of the central domain are dominant, and rapid elongation ensues.

Whether the disruption of NMII increases or decreases elongation depends on the substrate (Ketschek et al., 2007); when neurons are grown on polyamines, in the presence of growth inhibitory substrates such as CSPGs, or in the presence of low concentrations of laminin, growth is typically slow, and inhibition of NMII increases elongation (Ketschek et al., 2007; Hur et al., 2011). In contrast, growth on high concentrations of laminin is rapid but slowed by inhibition of NMII (Ketschek et al., 2007; Turney et al., 2016). As growth inhibitory substrates activate Rho (Monnier et al., 2003; Geoffroy and Zheng, 2014), these effects can be interpreted in the context of the differential activation of NMIIA along the axon.

To better understand the interplay between the substrate, NMII activity, and growth, Turney et al. (2016) recently investigated the mechanism underlying the promotion of neurite outgrowth by NGF on both fibronectin and laminin in embryonic mouse sensory neurons. They did so by systematically varying NGF concentration, the substrate, and NMII activity. They found NMII disruption blocked the growth promoting effect of NGF, but the mechanism depended on the substrate. On laminin, NGF had little effect on NMII activity as assessed by phosphorylated myosin light chain staining. Instead, it promoted growth by selectively shifting vinculin, which links actin to integrin, to the leading edge of the growth cone. Correlated with this shift, NGF increased traction forces and slowed retrograde flow. In contrast, when neurons were grown on fibronectin, NGF selectively decreased NMIIA activity. As these studies and our recent analysis of bulk MT motion were both conducted in sensory neurons grown on laminin, the possibility exists that the effects of NGF, substrate and NMII activity may be explained through a consideration of how they impact the forward flow of MTs and the motion of the transition zone (Athamneh et al., 2017). In concluding this section, we think it is important to note that our model of how NMII isoforms interact to control elongation is a working hypothesis (Figures 2, 6) and direct biophysical analysis of the role of NMII in sub-cellular force generation and bulk flow is needed to test it.

\section{The Importance of Actin Disassembly in Neurite Outgrowth}

Growth cone advance depends not only on actin assembly and NMII-actin interactions but also on actin disassembly (Figure 2). $\mathrm{ADF} /$ cofilins are tightly linked to this process because they promote actin turnover (Bamburg and Bernstein, 2010). They do so by selectively binding to F-actin bound to ADP, severing the filaments, and promoting disassembly at both ends (Wioland et al., 2017). During neurite elongation, inhibition of actin disassembly by either disruption of ADF/cofilin (Endo et al., 2003; Flynn et al., 2012) or with the actin-stabilizing drug jasplakinolide (Gallo et al., 2002; Van Goor et al., 2012), slows retrograde flow and growth cone advance. In contrast, activation of $\mathrm{ADF} /$ cofilin downstream of 5-HT increases elongation and retrograde flow (Zhang et al., 2012). The effect of ADF/cofilin in promoting growth has been suggested to occur in part because it creates a space that allows MT advance (Flynn et al., 2012). On the other hand, activation of $\mathrm{AC}$ downstream of repulsive cues leads to growth cone collapse paired with a decrease in growth cone F-actin (Hsieh et al., 2006; Piper et al., 2006). If actin filaments were a passive barrier to MT advance, one would predict elongation to increase. Likewise, the observation that both flow and growth slows when actin disassembly is inhibited challenges the hypothesis that that rapid retrograde actin flow is a kinetic barrier to MT advance (Lin and Forscher, 1995). A clue to this complex response comes from the observation that the inhibition of actin disassembly with jasplakinolide decreases traction forces by $\sim 50 \%$ (Hyland et al., 2014). As discussed above, viewing elongation as being controlled by force balance, the decrease in traction forces may explain why inhibition of actin disassembly slows elongation.

Why forces decrease when actin disassembly is inhibited is still poorly understood, but may occur because they are shunted toward breaking and compacting actin filaments, instead of pulling the substrate rearward (Medeiros et al., 2006; Craig et al., 2012; Vogel et al., 2013; McFadden et al., 2017). Similarly, loss of growth cone actin as the result of high $\mathrm{ADF} /$ cofilin activity may reduce traction forces through loss of linkages with the substrate. It is important to note that the biophysical effects of altering $\mathrm{ADF} /$ cofilin on growth cone traction forces are currently unknown. Furthermore, other effects such as a change in viscosity could explain these responses to changing actin disassembly (O’Toole et al., 2008a; de Rooij et al., 2018). Given our field's poor understanding of the interplay between actin dynamics and neuronal mechanics, we suggest it as a critical topic for deeper investigation.

\section{MT-Actin Interactions in Neurite Outgrowth}

How MTs and actin interact to drive axonal elongation is a difficult question (Coles and Bradke, 2015; Voelzmann et al., 2016). Again, applying ideas developed in physics with rigorous

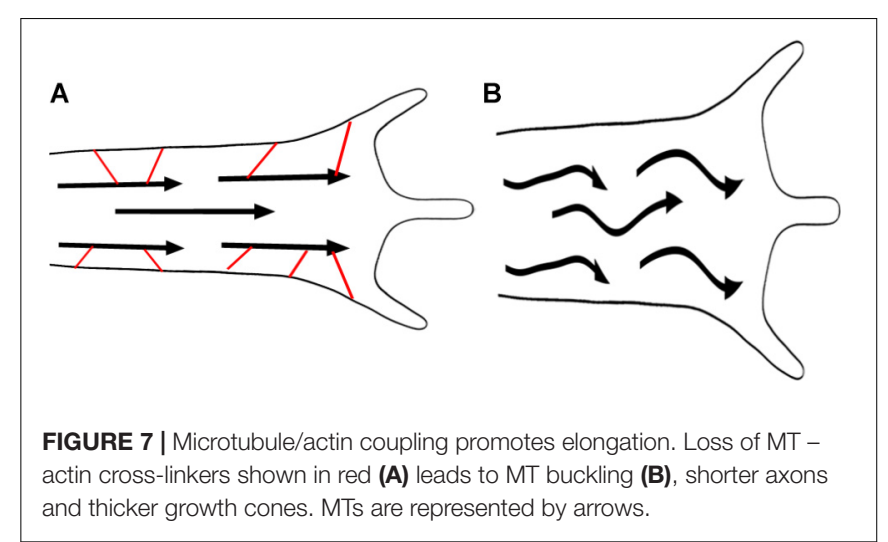


cell biology has the potential to transform our understanding. A growing array of MT plus-end tracking protein, direct crosslinkers, and cross-linking protein complexes have been identified as couplers between actin filaments and MTs (Figure 2). Invariably, disruption of these proteins alters elongation and guidance and leads to disordered MT arrays. An excellent illustration of this is shown in Drosophila neurons null for shot, the homolog of spectraplakin ACF7, where extensive MT buckling occurs in both the growth cone and along the axon (Alves-Silva et al., 2012). In parallel, theory to model the bending of rods in elastic matrixes and active fluids has been applied to better understand the relationship between MT bucking, forces and the influence of actin (Brangwynne et al., 2006; Kikuchi et al., 2009). When MTs are under compression in isolation, they buckle as rods described by the classic Euler buckling theorem. When MTs are embedded in an active fluid or elastic medium, such as actin filaments, instead of having a single $\mathrm{C}$ shaped curve, they assume a wavy S-shaped confirmation (Brangwynne et al., 2006). As the stiffness of the matrix increases, the number of bends (i.e., modes) and the force MTs bear increases, whereas the size of the bends (i.e., their amplitude) decreases (Brangwynne et al., 2006). With knowledge of the stiffness of MTs and the actin meshwork, the compressive force on MTs can be estimated based on their curvature. In neurons and other cells, this is on the order of $100 \mathrm{pN}$ with the caveats that density, orientation, and forces generated by actomyosin strongly impact this estimate (Brangwynne et al., 2006; Rauch et al., 2013).

When actin-MT cross-linkers are disrupted, it seems unlikely that either the compressive forces on MTs are higher or that the actin matrix is directly weakened. Nonetheless, as the coupling between actin filaments and MTs is decreased, it is possible that the 'effective' stiffness of the matrix is reduced. From this, the buckling of MTs observed when shot (Alves-Silva et al., 2012), tau (Biswas and Kalil, 2018), and other cross-linkers are disrupted may arise through a decreased physical interaction with the actin network (Figure 7). There are two important implications. The first is that without the stabilizing influence of actin, MTs will bear reduced compressive loads (Brangwynne et al., 2006). The second is that when MTs are disorganized, they will direct forces against the sides of the axon and growth cone (Alves-Silva et al., 2012). Bringing these ideas together provides a physical explanation for the large axonal varicosities filled with disorganized MTs and the widening of the growth cones observed when the actin-MT cross-linking function of tau is disrupted (Biswas and Kalil, 2018). More generally, a reduction in the net forward forces may explain why disorganized MTs are typically associated with reduced rates of axonal elongation. Collectively, these observations shift focus from models that propose elongation is driven by the pushing force of MT or actin assembly in the growth cone toward mechanisms involving MT sliding by motors and crosslinking to actin filaments.

\section{CONCLUSION AND OUTLOOK}

In conclusion, we propose here an integrated cytoskeletal model of neurite outgrowth (Figure 2), that does not pinpoint a single dynamic process as the sole driving force of elongation. We suggest that gradients in force generation and adhesions along the axon and growth cone determine whether axons elongate, retract, or stall. If the growth cone produces stronger traction forces and adhesions than the axon, the net result will be increased neurite growth. The second significant aspect of our model involves the idea that axons are active fluids and that viscosity controls the rate of material flow. In addition to force generation, cross-linkers between different types of filaments affect viscosity and control how quickly flow occurs in response to forces. Since cross-links are lost when filaments undergo disassembly, the dynamics of MTs and actin filaments impacts viscosity. In general, for fast growth to occur, the density of cross-linkers needs to be minimized, and the dynamics of filaments increased. On the other hand, if the density of cross-linkers drops too much, the forces generated by these systems may be less directed (Figure 7).

Viewing neurons as an active fluid leads to a model of elongation that is useful for understanding how growth occurs and further suggests principles for prompting rapid neurite growth for example during regeneration following injury. To promote rapid elongation, one needs to increase net contractile force generation and adhesions in front of the central domain, decrease net contractile force generation and adhesions along the axon, and lower viscosity (Figures 2, 6). As forces, adhesions, and viscosity are influenced by multiple processes; many approaches could lead to fast elongation. What complicates the development of therapies for neurite growth is that any given component is typically involved in several processes that often have opposing effects on elongation. However, without an integrated model, it will be challenging to come up with better approaches to increase neurite growth. We hope that this review will stimulate new developments in this area.

\section{AUTHOR CONTRIBUTIONS}

All authors listed have made a substantial, direct and intellectual contribution to the work, and approved it for publication.

\section{FUNDING}

This work was supported by the following grants: NSF 1146944IOS (to DS), Office of the Executive Vice President for Research at Purdue University (to DS), and NIH 1R01MH094607-01A1 (to KM).

\section{ACKNOWLEDGMENTS}

The authors thank Eva Miller for her helpful support in aiding the efforts of KM and Yuan Ren for providing the phase contrast image in Figure 1A. 


\section{REFERENCES}

Alves-Silva, J., Sanchez-Soriano, N., Beaven, R., Klein, M., Parkin, J., Millard, T. H., et al. (2012). Spectraplakins promote microtubule-mediated axonal growth by functioning as structural microtubule-associated proteins and EB1-dependent +TIPs (tip interacting proteins). J. Neurosci. 32, 9143-9158. doi: 10.1523/ JNEUROSCI.0416-12.2012

Amin, L., Ercolini, E., Ban, J., and Torre, V. (2013). Comparison of the force exerted by hippocampal and DRG growth cones. PLoS One 8:e73025. doi: 10.1371/journal.pone.0073025

Amin, L., Ercolini, E., Shahapure, R., Migliorini, E., and Torre, V. (2012). The role of membrane stiffness and actin turnover on the force exerted by DRG lamellipodia. Biophys. J. 102, 2451-2460. doi: 10.1016/j.bpj.2012.04.036

Athamneh, A. I., Cartagena-Rivera, A. X., Raman, A., and Suter, D. M. (2015). Substrate deformation predicts neuronal growth cone advance. Biophys. J. 109, 1358-1371. doi: 10.1016/j.bpj.2015.08.013

Athamneh, A. I., and Suter, D. M. (2015). Quantifying mechanical force in axonal growth and guidance. Front. Cell. Neurosci. 9:359. doi: 10.3389/fncel.2015.00359

Athamneh, A. I. M., He, Y., Lamoureux, P., Fix, L., Suter, D. M., and Miller, K. E. (2017). Neurite elongation is highly correlated with bulk forward translocation of microtubules. Sci. Rep. 7:7292. doi: 10.1038/s41598-017-07402-6

Baas, P. W. (1997). Microtubules and axonal growth. Curr. Opin. Cell Biol. 9, 29-36. doi: 10.1016/S0955-0674(97)80148-2

Baas, P. W., and Black, M. M. (1990). Individual microtubules in the axon consist of domains that differ in both composition and stability. J. Cell Biol. 111, 495-509. doi: $10.1083 /$ jcb.111.2.495

Baas, P. W., Black, M. M., and Banker, G. A. (1989). Changes in microtubule polarity orientation during the development of hippocampal neurons in culture. J. Cell Biol. 109(6 Pt 1), 3085-3094. doi: 10.1083/jcb.109.6.3085

Baas, P. W., Deitch, J. S., Black, M. M., and Banker, G. A. (1988). Polarity orientation of microtubules in hippocampal neurons: uniformity in the axon and nonuniformity in the dendrite. Proc. Natl. Acad. Sci. U.S.A. 85, 8335-8339. doi: $10.1073 /$ pnas.85.21.8335

Bamburg, J. R., and Bernstein, B. W. (2010). Roles of ADF/cofilin in actin polymerization and beyond. F1000 Biol. Rep. 2:62. doi: 10.3410/B2-62

Bamburg, J. R., Bray, D., and Chapman, K. (1986). Assembly of microtubules at the tip of growing axons. Nature 321, 788-790. doi: 10.1038/321788a0

Bard, L., Boscher, C., Lambert, M., Mege, R. M., Choquet, D., and Thoumine, O. (2008). A molecular clutch between the actin flow and $\mathrm{N}$-cadherin adhesions drives growth cone migration. J. Neurosci. 28, 5879-5890. doi: 10.1523/ JNEUROSCI.5331-07.2008

Bearer, E. L., and Reese, T. S. (1999). Association of actin filaments with axonal microtubule tracts. J. Neurocytol. 28, 85-98. doi: 10.1023/A:1007025421849

Benford, G. (1980). Timescape. New York, NY: Simon and Schuster.

Berger, S. L., Leo-Macias, A., Yuen, S., Khatri, L., Pfennig, S., Zhang, Y., et al. (2018). Localized myosin II activity regulates assembly and plasticity of the axon initial segment. Neuron 97, 555-570.e6. doi: 10.1016/j.neuron.2017.12.039

Bernal, R., Melo, F., and Pullarkat, P. A. (2010). Drag force as a tool to test the active mechanical response of PC12 neurites. Biophys. J. 98, 515-523. doi: 10.1016/j.bpj.2009.10.024

Bernal, R., Pullarkat, P. A., and Melo, F. (2007). Mechanical properties of axons. Phys. Rev. Lett. 99:018301. doi: 10.1103/PhysRevLett.99.018301

Betz, T., Koch, D., Lu, Y. B., Franze, K., and Kas, J. A. (2011). Growth cones as soft and weak force generators. Proc. Natl. Acad. Sci. U.S.A. 108, 13420-13425. doi: 10.1073/pnas.1106145108

Billington, N., Wang, A., Mao, J., Adelstein, R. S., and Sellers, J. R. (2013). Characterization of three full-length human nonmuscle myosin II paralogs. J. Biol. Chem. 288, 33398-33410. doi: 10.1074/jbc.M113.499848

Biswas, S., and Kalil, K. (2018). The microtubule-associated protein tau mediates the organization of microtubules and their dynamic exploration of actin-rich lamellipodia and filopodia of cortical growth cones. J. Neurosci. 38, 291-307. doi: 10.1523/JNEUROSCI.2281-17.2017

Blanquie, O., and Bradke, F. (2018). Cytoskeleton dynamics in axon regeneration. Curr. Opin. Neurobiol. 51, 60-69. doi: 10.1016/j.conb.2018.02.024

Brangwynne, C. P., MacKintosh, F. C., Kumar, S., Geisse, N. A., Talbot, J., Mahadevan, L., et al. (2006). Microtubules can bear enhanced compressive loads in living cells because of lateral reinforcement. J. Cell Biol. 173, 733-741. doi: $10.1083 /$ jcb. 200601060
Bray, D. (1984). Axonal growth in response to experimentally applied mechanical tension. Dev. Biol. 102, 379-389. doi: 10.1016/0012-1606(84)90202-1

Bray, D., and Bunge, M. B. (1981). Serial analysis of microtubules in cultured rat sensory axons. J. Neurocytol. 10, 589-605. doi: 10.1007/BF0126 2592

Bridgman, P. C. (2002). Growth cones contain myosin II bipolar filament arrays. Cell Motil. Cytoskeleton 52, 91-96. doi: 10.1002/cm.10038

Bridgman, P. C., Dave, S., Asnes, C. F., Tullio, A. N., and Adelstein, R. S. (2001) Myosin IIB is required for growth cone motility. J. Neurosci. 21, 6159-6169. doi: 10.1523/JNEUROSCI.21-16-06159.2001

Brown, J. A., Wysolmerski, R. B., and Bridgman, P. C. (2009). Dorsal root ganglion neurons react to semaphorin $3 \mathrm{~A}$ application through a biphasic response that requires multiple myosin II isoforms. Mol. Biol. Cell 20, 1167-1179. doi: 10. 1091/mbc.E08-01-0065

Buck, K. B., Schaefer, A. W., Schoonderwoert, V. T., Creamer, M. S., Dufresne, E. R., and Forscher, P. (2017). Local Arp2/3-dependent actin assembly modulates applied traction force during apCAM adhesion site maturation. Mol. Biol. Cell 28, 98-110. doi: 10.1091/mbc.E16-04-0228

Budday, S., Steinmann, P., and Kuhl, E. (2014). The role of mechanics during brain development. J. Mech. Phys. Solids 72, 75-92. doi: 10.1016/j.jmps.2014.07.010

Burton, P. R. (1987). Microtubules of frog olfactory axons: their length and number/axon. Brain Res. 409, 71-78. doi: 10.1016/0006-8993(87)90742-6

Buxbaum, R. E., and Heidemann, S. R. (1992). An absolute rate theory model for tension control of axonal elongation. J. Theor. Biol. 155, 409-426. doi: 10.1016/S0022-5193(05)80626-5

Callan-Jones, A. C., and Julicher, F. (2011). Hydrodynamics of active permeating gels. New J. Phys. 13:093027. doi: 10.1088/1367-2630/13/9/093027

Cammarata, G. M., Bearce, E. A., and Lowery, L. A. (2016). Cytoskeletal social networking in the growth cone: how +TIPs mediate microtubule-actin crosslinking to drive axon outgrowth and guidance. Cytoskeleton 73, 461-476. doi: $10.1002 / \mathrm{cm} .21272$

Canovic, E. P., Seidl, D. T., Polio, S. R., Oberai, A. A., Barbone, P. E., Stamenovic, D., et al. (2014). Biomechanical imaging of cell stiffness and prestress with subcellular resolution. Biomech. Model. Mechanobiol. 13, 665-678. doi: 10.1007/s10237-013-0526-8

Chalfie, M., and Thomson, J. N. (1979). Organization of neuronal microtubules in the nematode Caenorhabditis elegans. J. Cell Biol. 82, 278-289. doi: 10.1083/jcb. 82.1.278

Chan, C. E., and Odde, D. J. (2008). Traction dynamics of filopodia on compliant substrates. Science 322, 1687-1691. doi: 10.1126/science.1163595

Chang, S., Svitkina, T. M., Borisy, G. G., and Popov, S. V. (1999). Speckle microscopic evaluation of microtubule transport in growing nerve processes. Nat. Cell Biol. 1, 399-403. doi: 10.1038/15629

Chang, Y. C., Nalbant, P., Birkenfeld, J., Chang, Z. F., and Bokoch, G. M. (2008). GEF-H1 couples nocodazole-induced microtubule disassembly to cell contractility via RhoA. Mol. Biol. Cell 19, 2147-2153. doi: 10.1091/mbc.E0712-1269

Cojoc, D., Difato, F., Ferrari, E., Shahapure, R. B., Laishram, J., Righi, M., et al. (2007). Properties of the force exerted by filopodia and lamellipodia and the involvement of cytoskeletal components. PLoS One 2:e1072. doi: 10.1371/ journal.pone.0001072

Coles, C. H., and Bradke, F. (2015). Coordinating neuronal actin-microtubule dynamics. Curr. Biol. 25, R677-R691. doi: 10.1016/j.cub.2015.06.020

Craig, E. M., Van Goor, D., Forscher, P., and Mogilner, A. (2012). Membrane tension, myosin force, and actin turnover maintain actin treadmill in the nerve growth cone. Biophys. J. 102, 1503-1513. doi: 10.1016/j.bpj.2012. 03.003

Craig, E. M., Yeung, H. T., Rao, A. N., and Baas, P. W. (2017). Polarity sorting of axonal microtubules: a computational study. Mol. Biol. Cell 28, 3271-3285. doi: 10.1091/mbc.E17-06-0380

Davenport, R. W., Dou, P., Rehder, V., and Kater, S. B. (1993). A sensory role for neuronal growth cone filopodia. Nature 361, 721-724. doi: 10.1038/361721a0

de Rooij, R., and Kuhl, E. (2018). Microtubule polymerization and cross-link dynamics explain axonal stiffness and damage. Biophys. J. 114, 201-212. doi: 10.1016/j.bpj.2017.11.010

de Rooij, R., Kuhl, E., and Miller, K. (2018). Modeling the axon as an active partner with the growth cone in axonal elongation. Biophys. J. 115, 1783-1795. doi: 10.1016/j.bpj.2018.08.047 
de Rooij, R., Miller, K. E., and Kuhl, E. (2017). Modeling molecular mechanisms in the axon. Comput. Mech. 59, 523-537. doi: 10.1007/s00466-016-1359-y

Del Castillo, U., Lu, W., Winding, M., Lakonishok, M., and Gelfand, V. I. (2015a). Pavarotti/MKLP1 regulates microtubule sliding and neurite outgrowth in Drosophila neurons. Curr. Biol. 25, 200-205. doi: 10.1016/j.cub.2014. 11.008

del Castillo, U., Winding, M., Lu, W., and Gelfand, V. I. (2015b). Interplay between kinesin-1 and cortical dynein during axonal outgrowth and microtubule organization in Drosophila neurons. eLife 4:e10140. doi: 10.7554/eLife.10140

Dennerll, T. J., Joshi, H. C., Steel, V. L., Buxbaum, R. E., and Heidemann, S. R. (1988). Tension and compression in the cytoskeleton of PC-12 neurites. II: quantitative measurements. J. Cell Biol. 107, 665-674. doi: 10.1083/jcb.107. 2.665

Dennerll, T. J., Lamoureux, P., Buxbaum, R. E., and Heidemann, S. R. (1989). The cytomechanics of axonal elongation and retraction. J. Cell Biol. 109(6 Pt 1), 3073-3083. doi: $10.1083 /$ jcb.109.6.3073

Dent, E. W., and Gertler, F. B. (2003). Cytoskeletal dynamics and transport in growth cone motility and axon guidance. Neuron 40, 209-227. doi: 10.1016/ S0896-6273(03)00633-0

D’Este, E., Kamin, D., Gottfert, F., El-Hady, A., and Hell, S. W. (2015). STED nanoscopy reveals the ubiquity of subcortical cytoskeleton periodicity in living neurons. Cell Rep. 10, 1246-1251. doi: 10.1016/j.celrep.2015.02.007

Dogterom, M., and Yurke, B. (1997). Measurement of the force-velocity relation for growing microtubules. Science 278, 856-860. doi: 10.1126/science.278.5339.856

Duellberg, C., Trokter, M., Jha, R., Sen, I., Steinmetz, M. O., and Surrey, T. (2014). Reconstitution of a hierarchical + TIP interaction network controlling microtubule end tracking of dynein. Nat. Cell Biol. 16, 804-811. doi: 10.1038/ ncb2999

Endo, M., Ohashi, K., Sasaki, Y., Goshima, Y., Niwa, R., Uemura, T., et al. (2003). Control of growth cone motility and morphology by LIM kinase and Slingshot via phosphorylation and dephosphorylation of cofilin. J. Neurosci. 23, 2527-2537. doi: 10.1523/JNEUROSCI.23-07-02527.2003

Fan, A., Tofangchi, A., Kandel, M., Popescu, G., and Saif, T. (2017). Coupled circumferential and axial tension driven by actin and myosin influences in vivo axon diameter. Sci. Rep. 7:14188. doi: 10.1038/s41598-017-13830-1

Flynn, K. C., Hellal, F., Neukirchen, D., Jacob, S., Tahirovic, S., Dupraz, S., et al. (2012). ADF/cofilin-mediated actin retrograde flow directs neurite formation in the developing brain. Neuron 76, 1091-1107. doi: 10.1016/j.neuron.2012.09.038

Forscher, P., and Smith, S. J. (1988). Actions of cytochalasins on the organization of actin filaments and microtubules in a neuronal growth cone. J. Cell Biol. 107, 1505-1516. doi: 10.1083/jcb.107.4.1505

Franze, K., Janmey, P. A., and Guck, J. (2013). Mechanics in neuronal development and repair. Annu. Rev. Biomed. Eng. 15, 227-251. doi: 10.1146/annurev-bioeng071811-150045

Gallo, G. (2006). RhoA-kinase coordinates F-actin organization and myosin II activity during semaphorin-3A-induced axon retraction. J. Cell Sci. 119(Pt 16), 3413-3423. doi: 10.1242 /jcs. 03084

Gallo, G. (2013). Mechanisms underlying the initiation and dynamics of neuronal filopodia: from neurite formation to synaptogenesis. Int. Rev. Cell Mol. Biol. 301, 95-156. doi: 10.1016/B978-0-12-407704-1.00003-8

Gallo, G., Yee, H. F. Jr., and Letourneau, P. C. (2002). Actin turnover is required to prevent axon retraction driven by endogenous actomyosin contractility. J. Cell Biol. 158, 1219-1228. doi: 10.1083/jcb.200204140

Ganguly, A., Tang, Y., Wang, L., Ladt, K., Loi, J., Dargent, B., et al. (2015). A dynamic formin-dependent deep F-actin network in axons. J. Cell Biol. 210, 401-417. doi: 10.1083/jcb.201506110

Garate, F., Pertusa, M., Arana, Y., and Bernal, R. (2018). Non-invasive neurite mechanics in differentiated PC12 cells. Front. Cell. Neurosci. 12:194. doi: 10. 3389/fncel.2018.00194

Geoffroy, C. G., and Zheng, B. (2014). Myelin-associated inhibitors in axonal growth after CNS injury. Curr. Opin. Neurobiol. 27, 31-38. doi: 10.1016/j.conb. 2014.02.012

Golomb, E., Ma, X., Jana, S. S., Preston, Y. A., Kawamoto, S., Shoham, N. G., et al. (2004). Identification and characterization of nonmuscle myosin IIC, a new member of the myosin II family. J. Biol. Chem. 279, 2800-2808. doi: 10.1074/jbc.M309981200

Gomez, T. M., and Letourneau, P. C. (2014). Actin dynamics in growth cone motility and navigation. J. Neurochem. 129, 221-234. doi: 10.1111/jnc.12506
Greene, G. W., Anderson, T. H., Zeng, H., Zappone, B., and Israelachvili, J. N. (2009). Force amplification response of actin filaments under confined compression. Proc. Natl. Acad. Sci. U.S.A. 106, 445-449. doi: 10.1073/pnas. 0812064106

Grevesse, T., Dabiri, B. E., Parker, K. K., and Gabriele, S. (2015). Opposite rheological properties of neuronal microcompartments predict axonal vulnerability in brain injury. Sci. Rep. 5:9475. doi: 10.1038/srep09475

Hammarlund, M., Jorgensen, E. M., and Bastiani, M. J. (2007). Axons break in animals lacking beta-spectrin. J. Cell Biol. 176, 269-275. doi: 10.1083/jcb. 200611117

He, Y., Francis, F., Myers, K. A., Yu, W., Black, M. M., and Baas, P. W. (2005). Role of cytoplasmic dynein in the axonal transport of microtubules and neurofilaments. J. Cell Biol. 168, 697-703. doi: 10.1083/jcb.200407191

Heidemann, S. R. (1990). "Neuronal tip growth," in Tip Growth in Plant and Fungal Cells, ed. B. Heath (Amsterdam: Elsevier), 285-316. doi: 10.1016/B978-0-12335845-5.50014-8

Heidemann, S. R., and Bray, D. (2015). Tension-driven axon assembly: a possible mechanism. Front. Cell. Neurosci. 9:316. doi: 10.3389/fncel.2015.00316

Heidemann, S. R., Lamoureux, P., and Buxbaum, R. E. (1990). Growth cone behavior and production of traction force. J. Cell Biol. 111(5 Pt 1), 1949-1957. doi: $10.1083 /$ jcb.111.5.1949

Hill, S. E., Parmar, M., Gheres, K. W., Guignet, M. A., Huang, Y., Jackson, F. R., et al. (2012). Development of dendrite polarity in Drosophila neurons. Neural Dev. 7:34. doi: 10.1186/1749-8104-7-34

Hilton, B. J., and Bradke, F. (2017). Can injured adult CNS axons regenerate by recapitulating development? Development 144, 3417-3429. doi: 10.1242/dev. 148312

Hirokawa, N. (1982). Cross-linker system between neurofilaments, microtubules, and membranous organelles in frog axons revealed by the quick-freeze, deepetching method. J. Cell Biol. 94, 129-142. doi: 10.1083/jcb.94.1.129

Hirokawa, N., Funakoshi, S. T., and Takeda, S. (1997). Slow axonal transport: the subunit transport model. Trends Cell Biol. 7, 384-388. doi: 10.1016/S09628924(97)01133-1

Hochmuth, F. M., Shao, J. Y., Dai, J., and Sheetz, M. P. (1996). Deformation and flow of membrane into tethers extracted from neuronal growth cones. Biophys. J. 70, 358-369. doi: 10.1016/S0006-3495(96)79577-2

Hoffman, P. N., and Lasek, R. J. (1975). The slow component of axonal transport. Identification of major structural polypeptides of the axon and their generality among mammalian neurons. J. Cell Biol. 66, 351-366. doi: 10.1083/jcb.66. 2.351

Hsieh, S. H., Ferraro, G. B., and Fournier, A. E. (2006). Myelin-associated inhibitors regulate cofilin phosphorylation and neuronal inhibition through LIM kinase and Slingshot phosphatase. J. Neurosci. 26, 1006-1015. doi: 10.1523/ JNEUROSCI.2806-05.2006

Hur, E. M., Yang, I. H., Kim, D. H., Byun, J., Saijilafu, Xu, W. L., et al. (2011). Engineering neuronal growth cones to promote axon regeneration over inhibitory molecules. Proc. Natl. Acad. Sci. U.S.A. 108, 5057-5062. doi: 10.1073/ pnas. 1011258108

Hyland, C., Mertz, A. F., Forscher, P., and Dufresne, E. (2014). Dynamic peripheral traction forces balance stable neurite tension in regenerating Aplysia bag cell neurons. Sci. Rep. 4:4961. doi: 10.1038/srep04961

Jakobs, M., Franze, K., and Zemel, A. (2015). Force generation by molecularmotor-powered microtubule bundles; implications for neuronal polarization and growth. Front. Cell. Neurosci. 9:441. doi: 10.3389/fncel.2015. 00441

Jones, S. L., and Svitkina, T. M. (2016). Axon initial segment cytoskeleton: architecture, development, and role in neuron polarity. Neural Plast. 2016:6808293. doi: 10.1155/2016/6808293

Joshi, H. C., Chu, D., Buxbaum, R. E., and Heidemann, S. R. (1985). Tension and compression in the cytoskeleton of PC 12 neurites. J. Cell Biol. 101, 697-705. doi: $10.1083 /$ jcb.101.3.697

Julicher, F., Kruse, K., Prost, J., and Joanny, J. F. (2007). Active behavior of the cytoskeleton. Phys. Rep. Rev. Phys. Lett. 449, 3-28. doi: 10.1016/j.physrep.2007. 02.018

Kahn, O. I., and Baas, P. W. (2016). Microtubules and growth cones: motors drive the turn. Trends Neurosci. 39, 433-440. doi: 10.1016/j.tins.2016.04.009

Kapitein, L. C., and Hoogenraad, C. C. (2015). Building the neuronal microtubule cytoskeleton. Neuron 87, 492-506. doi: 10.1016/j.neuron.2015.05.046 
Ketschek, A. R., Jones, S. L., and Gallo, G. (2007). Axon extension in the fast and slow lanes: substratum-dependent engagement of myosin II functions. Dev. Neurobiol. 67, 1305-1320. doi: 10.1002/dneu.20455

Kikuchi, N., Ehrlicher, A., Koch, D., Kas, J. A., Ramaswamy, S., and Rao, M. (2009). Buckling, stiffening, and negative dissipation in the dynamics of a biopolymer in an active medium. Proc. Natl. Acad. Sci. U.S.A. 106, 19776-19779. doi: 10.1073/pnas.0900451106

Kilinc, D., Blasiak, A., O’Mahony, J. J., and Lee, G. U. (2014). Low piconewton towing of CNS axons against diffusing and surface-bound repellents requires the inhibition of motor protein-associated pathways. Sci. Rep. 4:7128. doi: 10 . 1038/srep07128

Koch, D., Rosoff, W. J., Jiang, J., Geller, H. M., and Urbach, J. S. (2012). Strength in the periphery: growth cone biomechanics and substrate rigidity response in peripheral and central nervous system neurons. Biophys. J. 102, 452-460. doi: 10.1016/j.bpj.2011.12.025

Koestler, S. A., Auinger, S., Vinzenz, M., Rottner, K., and Small, J. V. (2008). Differentially oriented populations of actin filaments generated in lamellipodia collaborate in pushing and pausing at the cell front. Nat. Cell Biol. 10, 306-313. doi: $10.1038 /$ ncb1692

Korobova, F., and Svitkina, T. (2008). Arp2/3 complex is important for filopodia formation, growth cone motility, and neuritogenesis in neuronal cells. Mol. Biol. Cell 19, 1561-1574. doi: 10.1091/mbc.E07-09-0964

Krieg, M., Dunn, A. R., and Goodman, M. B. (2014). Mechanical control of the sense of touch by beta-spectrin. Nat. Cell Biol. 16, 224-233. doi: 10.1038/ ncb2915

Krieg, M., Stuhmer, J., Cueva, J. G., Fetter, R., Spilker, K., Cremers, D., et al. (2017). Genetic defects in beta-spectrin and tau sensitize C. elegans axons to movement-induced damage via torque-tension coupling. eLife 6:e20172. doi: 10.7554/eLife.20172

Kubo, T., Endo, M., Hata, K., Taniguchi, J., Kitajo, K., Tomura, S., et al. (2008). Myosin IIA is required for neurite outgrowth inhibition produced by repulsive guidance molecule. J. Neurochem. 105, 113-126. doi: 10.1111/j.1471-4159.2007. 05125.x

Kubo, Y., Baba, K., Toriyama, M., Minegishi, T., Sugiura, T., Kozawa, S., et al. (2015). Shootin1-cortactin interaction mediates signal-force transduction for axon outgrowth. J. Cell Biol. 210, 663-676. doi: 10.1083/jcb.201505011

Kulkarni, V. A., and Firestein, B. L. (2012). The dendritic tree and brain disorders. Mol. Cell. Neurosci. 50, 10-20. doi: 10.1016/j.mcn.2012.03.005

Kumar, N., Soni, H., Ramaswamy, S., and Sood, A. K. (2014). Flocking at a distance in active granular matter. Nat. Commun. 5:4688. doi: 10.1038/ncomms5688

Lamoureux, P., Buxbaum, R. E., and Heidemann, S. R. (1989). Direct evidence that growth cones pull. Nature 340, 159-162. doi: 10.1038/340159a0

Lamoureux, P., Heidemann, S., and Miller, K. E. (2011). Mechanical manipulation of neurons to control axonal development. J. Vis. Exp. 50:2509. doi: 10.3791/ 2509

Lamoureux, P., Heidemann, S. R., Martzke, N. R., and Miller, K. E. (2010). Growth and elongation within and along the axon. Dev. Neurobiol. 70, 135-149. doi: 10.1002/dneu.20764

Lee, A. C., and Suter, D. M. (2008). Quantitative analysis of microtubule dynamics during adhesion-mediated growth cone guidance. Dev. Neurobiol. 68, 13631377. doi: 10.1002/dneu.20662

Lee, C. W., Vitriol, E. A., Shim, S., Wise, A. L., Velayutham, R. P., and Zheng, J. Q. (2013). Dynamic localization of G-actin during membrane protrusion in neuronal motility. Curr. Biol. 23, 1046-1056. doi: 10.1016/j.cub.2013.04.057

Leite, S. C., Sampaio, P., Sousa, V. F., Nogueira-Rodrigues, J., Pinto-Costa, R., Peters, L. L., et al. (2016). The actin-binding protein alpha-adducin is required for maintaining axon diameter. Cell Rep. 15, 490-498. doi: 10.1016/j.celrep. 2016.03.047

Leterrier, C., Dubey, P., and Roy, S. (2017). The nano-architecture of the axonal cytoskeleton. Nat. Rev. Neurosci. 18, 713-726. doi: 10.1038/nrn.2017.129

Letourneau, P. C. (2016). “Cytoskeleton in axon growth", in eLS, ed. P. C. Letourneau (Minneapolis, MN: University of Minnesota).

Lewis, A. K., and Bridgman, P. C. (1992). Nerve growth cone lamellipodia contain two populations of actin filaments that differ in organization and polarity. J. Cell Biol. 119, 1219-1243. doi: 10.1083/jcb.119.5.1219

Lim, S. S., Edson, K. J., Letourneau, P. C., and Borisy, G. G. (1990). A test of microtubule translocation during neurite elongation. J. Cell Biol. 111, 123-130. doi: $10.1083 /$ jcb.111.1.123
Limouze, J., Straight, A. F., Mitchison, T., and Sellers, J. R. (2004). Specificity of blebbistatin, an inhibitor of myosin II. J. Muscle Res. Cell Motil. 25, 337-341. doi: 10.1007/s10974-004-6060-7

Lin, C. H., and Forscher, P. (1995). Growth cone advance is inversely proportional to retrograde F-actin flow. Neuron 14, 763-771. doi: 10.1016/0896-6273(95) 90220-1

Lin, S., Liu, M., Mozgova, O. I., Yu, W., and Baas, P. W. (2012). Mitotic motors coregulate microtubule patterns in axons and dendrites. J. Neurosci. 32, 14033 14049. doi: 10.1523/JNEUROSCI.3070-12.2012

Lopez, H. M., Gachelin, J., Douarche, C., Auradou, H., and Clement, E. (2015). Turning bacteria suspensions into superfluids. Phys. Rev. Lett. 115:028301. doi: 10.1103/PhysRevLett.115.028301

Loverde, J. R., and Pfister, B. J. (2015). Developmental axon stretch stimulates neuron growth while maintaining normal electrical activity, intracellular calcium flux, and somatic morphology. Front. Cell. Neurosci. 9:308. doi: 10. 3389/fncel.2015.00308

Lu, M., Witke, W., Kwiatkowski, D. J., and Kosik, K. S. (1997). Delayed retraction of filopodia in gelsolin null mice. J. Cell Biol. 138, 1279-1287. doi: 10.1083/jcb. 138.6.1279

Lu, W., Fox, P., Lakonishok, M., Davidson, M. W., and Gelfand, V. I. (2013). Initial neurite outgrowth in Drosophila neurons is driven by kinesin-powered microtubule sliding. Curr. Biol. 23, 1018-1023. doi: 10.1016/j.cub.2013.04.050

Lu, W., and Gelfand, V. I. (2017). Moonlighting motors: kinesin, dynein, and cell polarity. Trends Cell Biol. 27, 505-514. doi: 10.1016/j.tcb.2017.02.005

Maday, S., Twelvetrees, A. E., Moughamian, A. J., and Holzbaur, E. L. (2014). Axonal transport: cargo-specific mechanisms of motility and regulation. Neuron 84, 292-309. doi: 10.1016/j.neuron.2014.10.019

Mallavarapu, A., and Mitchison, T. (1999). Regulated actin cytoskeleton assembly at filopodium tips controls their extension and retraction. J. Cell Biol. 146, 1097-1106. doi: 10.1083/jcb.146.5.1097

Maniar, T. A., Kaplan, M., Wang, G. J., Shen, K., Wei, L., Shaw, J. E., et al. (2011). UNC-33 (CRMP) and ankyrin organize microtubules and localize kinesin to polarize axon-dendrite sorting. Nat. Neurosci. 15, 48-56. doi: 10.1038/nn.2970

Marchetti, M. C., Joanny, J. F., Ramaswamy, S., Liverpool, T. B., Prost, J., Rao, M. et al. (2013). Hydrodynamics of soft active matter. Rev. Mod. Phys. 85:1143. doi: 10.1103/RevModPhys.85.1143

Marsick, B. M., Flynn, K. C., Santiago-Medina, M., Bamburg, J. R., and Letourneau, P. C. (2010). Activation of ADF/cofilin mediates attractive growth cone turning toward nerve growth factor and netrin-1. Dev. Neurobiol. 70, 565-588. doi: 10.1002/dneu.20800

Matamoros, A. J., and Baas, P. W. (2016). Microtubules in health and degenerative disease of the nervous system. Brain Res. Bull. 126(Pt 3), 217-225. doi: 10.1016/ j.brainresbull.2016.06.016

McFadden, W. M., McCall, P. M., Gardel, M. L., and Munro, E. M. (2017). Filament turnover tunes both force generation and dissipation to control longrange flows in a model actomyosin cortex. PLoS Comput. Biol. 13:e1005811. doi: 10.1371/journal.pcbi.1005811

Medeiros, N. A., Burnette, D. T., and Forscher, P. (2006). Myosin II functions in actin-bundle turnover in neuronal growth cones. Nat. Cell Biol. 8, 215-226. doi: $10.1038 /$ ncb1367

Miller, K. E., and Samuels, D. C. (1997). The axon as a metabolic compartment: protein degradation, transport, and maximum length of an axon. J. Theor. Biol. 186, 373-379. doi: 10.1006/jtbi.1996.0355

Miller, K. E., and Sheetz, M. P. (2004). Axonal mitochondrial transport and potential are correlated. J. Cell Sci. 117(Pt 13), 2791-2804. doi: 10.1242/jcs. 01130

Miller, K. E., and Sheetz, M. P. (2006). Direct evidence for coherent low velocity axonal transport of mitochondria. J. Cell Biol. 173, 373-381. doi: 10.1083/jcb. 200510097

Mitchison, T., and Kirschner, M. (1988). Cytoskeletal dynamics and nerve growth. Neuron 1, 761-772. doi: 10.1016/0896-6273(88)90 124-9

Mongiu, A. K., Weitzke, E. L., Chaga, O. Y., and Borisy, G. G. (2007). Kineticstructural analysis of neuronal growth cone veil motility. J. Cell Sci. 120(Pt 6), 1113-1125. doi: 10.1242/jcs.03384

Monnier, P. P., Sierra, A., Schwab, J. M., Henke-Fahle, S., and Mueller, B. K. (2003). The Rho/ROCK pathway mediates neurite growth-inhibitory activity associated with the chondroitin sulfate proteoglycans of the CNS 
glial scar. Mol. Cell. Neurosci. 22, 319-330. doi: 10.1016/S1044-7431(02)0 0035-0

Morrison, E. E., Wardleworth, B. N., Askham, J. M., Markham, A. F., and Meredith, D. M. (1998). EB1, a protein which interacts with the APC tumour suppressor, is associated with the microtubule cytoskeleton throughout the cell cycle. Oncogene 17, 3471-3477. doi: 10.1038/sj.onc.1202247

Murray, A., Naeem, A., Barnes, S. H., Drescher, U., and Guthrie, S. (2010). Slit and Netrin-1 guide cranial motor axon pathfinding via Rho-kinase, myosin light chain kinase and myosin II. Neural Dev. 5:16. doi: 10.1186/1749-81 04-5-16

Mutalik, S. P., Joseph, J., Pullarkat, P. A., and Ghose, A. (2018). Cytoskeletal mechanisms of axonal contractility. Biophys. J. 115, 713-724. doi: 10.1016/j.bpj. 2018.07.007

Myers, K. A., Tint, I., Nadar, C. V., He, Y., Black, M. M., and Baas, P. W. (2006). Antagonistic forces generated by cytoplasmic dynein and myosin-II during growth cone turning and axonal retraction. Traffic 7, 1333-1351. doi: 10.1111/ j.1600-0854.2006.00476.x

Nichol, R. I., Hagen, K. M., Lumbard, D. C., Dent, E. W., and Gomez, T. M. (2016). Guidance of axons by local coupling of retrograde flow to point contact adhesions. J. Neurosci. 36, 2267-2282. doi: 10.1523/JNEUROSCI.2645-15.2016

Niederman, R., and Pollard, T. D. (1975). Human platelet myosin. II. In vitro assembly and structure of myosin filaments. J. Cell Biol. 67, 72-92. doi: 10.1083/ jcb.67.1.72

Okabe, S., and Hirokawa, N. (1990). Turnover of fluorescently labelled tubulin and actin in the axon. Nature 343, 479-482. doi: 10.1038/343479a0

Omotade, O. F., Pollitt, S. L., and Zheng, J. Q. (2017). Actin-based growth cone motility and guidance. Mol. Cell. Neurosci. 84, 4-10. doi: 10.1016/j.mcn.2017. 03.001

O’Toole, M., Lamoureux, P., and Miller, K. E. (2008a). A physical model of axonal elongation: force, viscosity, and adhesions govern the mode of outgrowth. Biophys. J. 94, 2610-2620. doi: 10.1529/biophysj.107.117424

O'Toole, M., Latham, R., Baqri, R. M., and Miller, K. E. (2008b). Modeling mitochondrial dynamics during in vivo axonal elongation. J. Theor. Biol. 255, 369-377. doi: 10.1016/j.jtbi.2008.09.009

O’Toole, M., Lamoureux, P., and Miller, K. E. (2015). Measurement of subcellular force generation in neurons. Biophys. J. 108, 1027-1037. doi: 10.1016/j.bpj.2015. 01.021

O’Toole, M., and Miller, K. E. (2011). The role of stretching in slow axonal transport. Biophys. J. 100, 351-360. doi: 10.1016/j.bpj.2010.12.3695

Papandreou, M. J., and Leterrier, C. (2018). The functional architecture of axonal actin. Mol. Cell. Neurosci. 91, 151-159. doi: 10.1016/j.mcn.2018.05.003

Park, C. Y., Tambe, D., Alencar, A. M., Trepat, X., Zhou, E. H., Millet, E., et al. (2010). Mapping the cytoskeletal prestress. Am. J. Physiol. Cell Physiol. 298, C1245-C1252. doi: 10.1152/ajpcell.00417.2009

Pfenninger, K. H. (1986). Of nerve growth cones, leukocytes and memory - 2nd messenger systems and growth-regulated proteins. Trends Neurosci. 9, 562-565. doi: 10.1016/0166-2236(86)90177-3

Piper, M., Anderson, R., Dwivedy, A., Weinl, C., van Horck, F., Leung, K. M., et al. (2006). Signaling mechanisms underlying Slit2-induced collapse of Xenopus retinal growth cones. Neuron 49, 215-228. doi: 10.1016/j.neuron.2005.12.008

Prass, M., Jacobson, K., Mogilner, A., and Radmacher, M. (2006). Direct measurement of the lamellipodial protrusive force in a migrating cell. J. Cell Biol. 174, 767-772. doi: 10.1083/jcb.200601159

Prost, J., Julicher, F., and Joanny, J. F. (2015). Active gel physics. Nat. Phys. 11, 111-117. doi: 10.1038/Nphys3224

Purohit, P. K. (2015). Tension dependent growth and retraction of neurites. Procedia IUTAM 12, 185-192. doi: 10.1016/j.piutam.2014.12.020

Qiang, L., Sun, X., Austin, T. O., Muralidharan, H., Jean, D. C., Liu, M., et al. (2018). Tau does not stabilize axonal microtubules but rather enables them to have long labile domains. Curr. Biol. 28, 2181-2189.e4. doi: 10.1016/j.cub.2018.05.045

Quiroga, S., Bisbal, M., and Caceres, A. (2018). Regulation of plasma membrane expansion during axon formation. Dev. Neurobiol. 78, 170-180. doi: 10.1002/ dneu. 22553

Rajagopalan, J., and Saif, M. T. (2011). MEMS sensors and microsystems for cell mechanobiology. J. Micromech. Microeng. 21, 54002-54012. doi: 10.1088/0960$1317 / 21 / 5 / 054002$

Ramón y Cajal, S. (1995). Histology of the Nervous System of Man and Vertebrates. New York, NY: Oxford University Press.
Rao, A. N., and Baas, P. W. (2018). Polarity sorting of microtubules in the axon. Trends Neurosci. 41, 77-88. doi: 10.1016/j.tins.2017.11.002

Rao, A. N., Patil, A., Black, M. M., Craig, E. M., Myers, K. A., Yeung, H. T., et al. (2017). Cytoplasmic dynein transports axonal microtubules in a polaritysorting manner. Cell Rep. 19, 2210-2219. doi: 10.1016/j.celrep.2017.05.064

Rauch, P., Heine, P., Goettgens, B., and Kas, J. A. (2013). Forces from the rear: deformed microtubules in neuronal growth cones influence retrograde flow and advancement. New J. Phys. 15:015007. doi: 10.1088/1367-2630/15/1/01 5007

Recho, P., Jerusalem, A., and Goriely, A. (2016). Growth, collapse, and stalling in a mechanical model for neurite motility. Phys. Rev. E Stat. Nonlin. Soft Matter Phys. 93:032410. doi: 10.1103/PhysRevE.93.032410

Reinsch, S. S., Mitchison, T. J., and Kirschner, M. (1991). Microtubule polymer assembly and transport during axonal elongation. J. Cell Biol. 115, 365-379. doi: $10.1083 /$ jcb.115.2.365

Ren, Y., and Suter, D. M. (2016). Increase in growth cone size correlates with decrease in neurite growth rate. Neural Plast. 2016:3497901. doi: 10.1155/2016/ 3497901

Rochlin, M. W., Dailey, M. E., and Bridgman, P. C. (1999). Polymerizing microtubules activate site-directed F-actin assembly in nerve growth cones. Mol. Biol. Cell 10, 2309-2327. doi: 10.1091/mbc.10.7.2309

Rochlin, M. W., Itoh, K., Adelstein, R. S., and Bridgman, P. C. (1995). Localization of myosin II A and B isoforms in cultured neurons. J. Cell Sci. 108(Pt 12), 3661-3670.

Rolls, M. M., and Jegla, T. J. (2015). Neuronal polarity: an evolutionary perspective. J. Exp. Biol. 218(Pt 4), 572-580. doi: 10.1242/jeb.11 2359

Roossien, D. H., Lamoureux, P., and Miller, K. E. (2014). Cytoplasmic dynein pushes the cytoskeletal meshwork forward during axonal elongation. J. Cell Sci. 127(Pt 16), 3593-3602. doi: 10.1242/jcs.152611

Roossien, D. H., Lamoureux, P., Van Vactor, D., and Miller, K. E. (2013). Drosophila growth cones advance by forward translocation of the neuronal cytoskeletal meshwork in vivo. PLoS One 8:e80136. doi: 10.1371/journal.pone. 0080136

Roy, S. (2016). Waves, rings, and trails: the scenic landscape of axonal actin. J. Cell Biol. 212, 131-134. doi: 10.1083/jcb.201511016

Schaefer, A. W., Kabir, N., and Forscher, P. (2002). Filopodia and actin arcs guide the assembly and transport of two populations of microtubules with unique dynamic parameters in neuronal growth cones. J. Cell Biol. 158, 139-152. doi: $10.1083 /$ jcb. 200203038

Schaefer, A. W., Schoonderwoert, V. T., Ji, L., Mederios, N., Danuser, G., and Forscher, P. (2008). Coordination of actin filament and microtubule dynamics during neurite outgrowth. Dev. Cell 15, 146-162. doi: 10.1016/j.devcel.2008. 05.003

Sens, P., and Plastino, J. (2015). Membrane tension and cytoskeleton organization in cell motility. J. Phys. Condens. Matter 27:273103. doi: 10.1088/0953-8984/27/ $27 / 273103$

Shahapure, R., Difato, F., Laio, A., Bisson, G., Ercolini, E., Amin, L., et al. (2010). Force generation in lamellipodia is a probabilistic process with fast growth and retraction events. Biophys. J. 98, 979-988. doi: 10.1016/j.bpj.2009. 11.041

Sheng, Z. H., and Cai, Q. (2012). Mitochondrial transport in neurons: impact on synaptic homeostasis and neurodegeneration. Nat. Rev. Neurosci. 13, 77-93. doi: $10.1038 / \mathrm{nrn} 3156$

Shimada, T., Toriyama, M., Uemura, K., Kamiguchi, H., Sugiura, T., Watanabe, N., et al. (2008). Shootin1 interacts with actin retrograde flow and L1-CAM to promote axon outgrowth. J. Cell Biol. 181, 817-829. doi: 10.1083/jcb.2007 12138

Shutova, M. S., and Svitkina, T. M. (2018). Mammalian nonmuscle myosin II comes in three flavors. Biochem. Biophys. Res. Commun. doi: 10.1016/j.bbrc.2018.03. 103 [Epub ahead of print].

Siechen, S., Yang, S., Chiba, A., and Saif, T. (2009). Mechanical tension contributes to clustering of neurotransmitter vesicles at presynaptic terminals. Proc. Natl. Acad. Sci. U.S.A. 106, 12611-12616. doi: 10.1073/pnas.090186 7106

Small, J. V., Stradal, T., Vignal, E., and Rottner, K. (2002). The lamellipodium: where motility begins. Trends Cell Biol. 12, 112-120. doi: 10.1016/S09628924(01)02237-1 
Smith, D. H. (2009). Stretch growth of integrated axon tracts: extremes and exploitations. Prog. Neurobiol. 89, 231-239. doi: 10.1016/j.pneurobio.2009. 07.006

Spedden, E., and Staii, C. (2013). Neuron biomechanics probed by atomic force microscopy. Int. J. Mol. Sci. 14, 16124-16140. doi: 10.3390/ijms140816124

Stepanova, T., Smal, I., van Haren, J., Akinci, U., Liu, Z., Miedema, M., et al. (2010). History-dependent catastrophes regulate axonal microtubule behavior. Curr. Biol. 20, 1023-1028. doi: 10.1016/j.cub.2010. 04.024

Stoeckli, E. T. (2018). Understanding axon guidance: are we nearly there yet? Development 145:dev151415. doi: 10.1242/dev.151415

Suter, D. M., Errante, L. D., Belotserkovsky, V., and Forscher, P. (1998). The Ig superfamily cell adhesion molecule, apCAM, mediates growth cone steering by substrate-cytoskeletal coupling. J. Cell Biol. 141, 227-240. doi: 10.1083/jcb.141. 1.227

Suter, D. M., and Forscher, P. (2000). Substrate-cytoskeletal coupling as a mechanism for the regulation of growth cone motility and guidance. J. Neurobiol. 44, 97-113. doi: 10.1002/1097-4695(200008)44:2<97::AIDNEU2>3.0.CO;2- U

Suter, D. M., and Forscher, P. (2001). Transmission of growth cone traction force through apCAM-cytoskeletal linkages is regulated by Src family tyrosine kinase activity. J. Cell Biol. 155, 427-438. doi: 10.1083/jcb.200107063

Suter, D. M., and Miller, K. E. (2011). The emerging role of forces in axonal elongation. Prog. Neurobiol. 94, 91-101. doi: 10.1016/j.pneurobio.2011.04.002

Takano, T., Wu, M., Nakamuta, S., Naoki, H., Ishizawa, N., Namba, T., et al. (2017). Discovery of long-range inhibitory signaling to ensure single axon formation. Nat. Commun. 8:33. doi: 10.1038/s41467-017-00044-2

Tanaka, E., Ho, T., and Kirschner, M. W. (1995). The role of microtubule dynamics in growth cone motility and axonal growth. J. Cell Biol. 128, 139-155. doi: $10.1083 /$ jcb.128.1.139

Tanaka, E. M., and Kirschner, M. W. (1991). Microtubule behavior in the growth cones of living neurons during axon elongation. J. Cell Biol. 115, 345-363. doi: $10.1083 /$ jcb.115.2.345

Tang-Schomer, M. D., Patel, A. R., Baas, P. W., and Smith, D. H. (2010). Mechanical breaking of microtubules in axons during dynamic stretch injury underlies delayed elasticity, microtubule disassembly, and axon degeneration. FASEB J. 24, 1401-1410. doi: 10.1096/fj.09-142844

Tofangchi, A., Fan, A., and Saif, M. T. A. (2016). Mechanism of axonal contractility in embryonic drosophila motor neurons in vivo. Biophys. J. 111, 1519-1527. doi: 10.1016/j.bpj.2016.08.024

Toriyama, M., Kozawa, S., Sakumura, Y., and Inagaki, N. (2013). Conversion of a signal into forces for axon outgrowth through Pak1-mediated shootin1 phosphorylation. Curr. Biol. 23, 529-534. doi: 10.1016/j.cub.2013.02.017

Turney, S. G., Ahmed, M., Chandrasekar, I., Wysolmerski, R. B., Goeckeler, Z. M., Rioux, R. M., et al. (2016). Nerve growth factor stimulates axon outgrowth through negative regulation of growth cone actomyosin restraint of microtubule advance. Mol. Biol. Cell 27, 500-517. doi: 10.1091/mbc.E15-090636

van Beuningen, S. F. B., Will, L., Harterink, M., Chazeau, A., van Battum, E. Y., Frias, C. P., et al. (2015). TRIM46 controls neuronal polarity and axon specification by driving the formation of parallel microtubule arrays. Neuron 88, 1208-1226. doi: 10.1016/j.neuron.2015.11.012

Van Goor, D., Hyland, C., Schaefer, A. W., and Forscher, P. (2012). The role of actin turnover in retrograde actin network flow in neuronal growth cones. PLoS One 7:e30959. doi: 10.1371/journal.pone.0030959

Voelzmann, A., Hahn, I., Pearce, S. P., Sanchez-Soriano, N., and Prokop, A. (2016). A conceptual view at microtubule plus end dynamics in neuronal axons. Brain Res. Bull. 126(Pt 3), 226-237. doi: 10.1016/j.brainresbull.2016.08.006

Vogel, S. K., Petrasek, Z., Heinemann, F., and Schwille, P. (2013). Myosin motors fragment and compact membrane-bound actin filaments. eLife 2:e00116. doi: 10.7554/eLife.00116

Wahl, S., Barth, H., Ciossek, T., Aktories, K., and Mueller, B. K. (2000). Ephrin-A5 induces collapse of growth cones by activating Rho and Rho kinase. J. Cell Biol. 149, 263-270. doi: 10.1083/jcb.149.2.263

Wang, L., and Brown, A. (2002). Rapid movement of microtubules in axons. Curr. Biol. 12, 1496-1501. doi: 10.1016/S0960-9822(02)01078-3
Wang, Y., Xu, Y., Liu, Q., Zhang, Y., Gao, Z., Yin, M., et al. (2017). Myosin IIArelated actomyosin contractility mediates oxidative stress-induced neuronal apoptosis. Front. Mol. Neurosci. 10:75. doi: 10.3389/fnmol.2017.00075

Winding, M., Kelliher, M. T., Lu, W., Wildonger, J., and Gelfand, V. I. (2016). Role of kinesin-1-based microtubule sliding in Drosophila nervous system development. Proc. Natl. Acad. Sci. U.S.A. 113, E4985-E4994. doi: 10.1073/pnas. 1522416113

Wioland, H., Guichard, B., Senju, Y., Myram, S., Lappalainen, P., Jegou, A., et al. (2017). ADF/cofilin accelerates actin dynamics by severing filaments and promoting their depolymerization at both ends. Curr. Biol. 27, 1956-1967.e7. doi: 10.1016/j.cub.2017.05.048

Wu, K. T., Hishamunda, J. B., Chen, D. T., DeCamp, S. J., Chang, Y. W., Fernandez-Nieves, A., et al. (2017). Transition from turbulent to coherent flows in confined three-dimensional active fluids. Science 355:eaal1979. doi: 10.1126/ science.aal1979

Wylie, S. R., and Chantler, P. D. (2001). Separate but linked functions of conventional myosins modulate adhesion and neurite outgrowth. Nat. Cell Biol. 3, 88-92. doi: $10.1038 / 35050613$

Wylie, S. R., and Chantler, P. D. (2003). Myosin IIA drives neurite retraction. Mol. Biol. Cell 14, 4654-4666. doi: 10.1091/mbc.e03-03-0187

Wylie, S. R., and Chantler, P. D. (2008). Myosin IIC: a third molecular motor driving neuronal dynamics. Mol. Biol. Cell 19, 3956-3968. doi: 10.1091/mbc. E07-08-0744

Xiong, Y., Lee, A. C., Suter, D. M., and Lee, G. U. (2009). Topography and nanomechanics of live neuronal growth cones analyzed by atomic force microscopy. Biophys. J. 96, 5060-5072. doi: 10.1016/j.bpj.2009. 03.032

Xu, K., Zhong, G., and Zhuang, X. (2013). Actin, spectrin, and associated proteins form a periodic cytoskeletal structure in axons. Science 339, 452-456. doi: 10.1126/science.1232251

Yau, K. W., Schatzle, P., Tortosa, E., Pages, S., Holtmaat, A., Kapitein, L. C., et al. (2016). Dendrites in vitro and in vivo contain microtubules of opposite polarity and axon formation correlates with uniform plus-end-out microtubule orientation. J. Neurosci. 36, 1071-1085. doi: 10.1523/JNEUROSCI.2430-15. 2016

Yogev, S., Cooper, R., Fetter, R., Horowitz, M., and Shen, K. (2016). Microtubule organization determines axonal transport dynamics. Neuron 92, 449-460. doi: 10.1016/j.neuron.2016.09.036

Yu, W., and Baas, P. W. (1994). Changes in microtubule number and length during axon differentiation. J. Neurosci. 14(5 Pt 1), 2818-2829. doi: 10.1523/ JNEUROSCI.14-05-02818.1994

Zhang, X. F., Hyland, C., Van Goor, D., and Forscher, P. (2012). Calcineurindependent cofilin activation and increased retrograde actin flow drive 5-HTdependent neurite outgrowth in Aplysia bag cell neurons. Mol. Biol. Cell 23, 4833-4848. doi: 10.1091/mbc.E12-10-0715

Zhang, X. F., Schaefer, A. W., Burnette, D. T., Schoonderwoert, V. T., and Forscher, P. (2003). Rho-dependent contractile responses in the neuronal growth cone are independent of classical peripheral retrograde actin flow. Neuron 40, 931-944. doi: 10.1016/S0896-6273(03)00754-2

Zheng, J., Lamoureux, P., Santiago, V., Dennerll, T., Buxbaum, R. E., and Heidemann, S. R. (1991). Tensile regulation of axonal elongation and initiation. J. Neurosci. 11, 1117-1125. doi: 10.1523/JNEUROSCI.11-04-01117.1991

Zhong, G., He, J., Zhou, R., Lorenzo, D., Babcock, H. P., Bennett, V., et al. (2014). Developmental mechanism of the periodic membrane skeleton in axons. eLife 3:e04581. doi: 10.7554/eLife.04581

Conflict of Interest Statement: The authors declare that the research was conducted in the absence of any commercial or financial relationships that could be construed as a potential conflict of interest.

Copyright (c) 2018 Miller and Suter. This is an open-access article distributed under the terms of the Creative Commons Attribution License (CC BY). The use, distribution or reproduction in other forums is permitted, provided the original author(s) and the copyright owner(s) are credited and that the original publication in this journal is cited, in accordance with accepted academic practice. No use, distribution or reproduction is permitted which does not comply with these terms. 